\title{
Una revolución en permanente debate. Acercamiento a los estudios de la Revolución rusa
}

\author{
JULIÁN VADILlo MUÑoz \\ Universidad Complutense de Madrid (España) \\ orcid.org/0000-0002-2392-3620
}

Presentación: 1 oct. 2018 | Aceptación: 21 nov. 2018 | Publicación: 15 des. 2018

Citación recomendada: Vadillo Muñoz, Julián. 2018. «Una revolución en permanente debate. Acercamiento a los estudios de la Revolución rusa». Dictatorships \& Democracies. Journal of History and Culture 6: 235-287. doi: https://dx.doi.org/10.7238/dd.voi6.3150.

Resumen: La Revolución rusa fue el principal acontecimiento de la historia del siglo xx y marcó la política internacional desde la llegada de los bolcheviques al poder en octubre de 1917. Ello hizo que este suceso se convirtiese en objeto de estudio y debate por parte de historiadores, profesores, ensayistas y periodistas. La producción bibliográfica del acontecimiento fue innumerable desde el mismo momento de su desarrollo. En el presente artículo se analizan las principales obras que se han escrito sobre el proceso revolucionario y las líneas de investigación abiertas al respecto.

Palabras clave: Revolución rusa, bolchevismo, leninismo, marxismo, conservadurismo

\begin{abstract}
A Revolution on Permanent Debate. Approaching Russian Revolution Studies
Abstract: The Russian Revolution was the main event in the history of the 2oth century and marked international politics since the Bolsheviks came to power in October 1917. As a result of it, this episode became an object of study and debate for historians, professors, essayists and journalists. The bibliographic production on the Russian Revolution was innumerable from the very moment it started. In this article we analyse the main works that have been written about the event and the lines of investigation opened in this regard.
\end{abstract}

Keywords: Russian Revolution, Bolshevism, Leninism, Marxism, Conservatism

\section{Introducción}

La Revolución rusa es, junto con la Guerra Civil española y la Segunda Guerra Mundial, uno de los acontecimientos que mayor número de libros ha generado desde su desarrollo, no solo porque fue un acontecimiento que cambió de forma radical la fisonomía del mundo, sino porque las ideas de las que partió y exportó cambiaron su entorno. También porque los 
dirigentes de ese proceso revolucionario serían protagonistas de ríos de tinta para analizar su vida, sus obras y sus ideas. La Revolución rusa cambió la historia inmediata, pues no solo fue una transformación en Rusia, sino que agitó las conciencias de miles y miles de personas que intentaron emular el proceso o bien abortar cualquier intento de poder plasmarlo en otro lugar. Igualmente, porque la Revolución rusa fue el inicio de lo que posteriormente cristalizaría en la Unión de Repúblicas Socialistas Soviéticas (URSS) y que marcaría la historia de la humanidad durante sus casi 75 años de existencia. Sin la Revolución rusa no se entiende el mundo polarizado que se desarrolló entre 1945 y 1991, aunque las ideas de aquella URSS hubiesen cambiado respecto a sus orígenes. Además, incluso tras su desaparición, la Revolución rusa sigue siendo un acontecimiento que marca los ritmos y la forma de pensar. Como dice el profesor Josep Fontana a tenor del centenario de la Revolución rusa en 2017: «Uno de esos intentos de transformación social, que se inició en Rusia en 1917, ha marcado la trayectoria de los cien años transcurridos desde entonces». ${ }^{1}$

Estamos, pues, ante lo que se puede considerar uno de los acontecimientos más importantes — por no decir el más importante — del siglo xx y que marcará el devenir del mismo. Como dijo Moshe Lewin, el siglo xx fue un «siglo soviético». ${ }^{2}$ La enorme producción bibliográfica que ha suscitado la Revolución rusa hace imposible resumirla en pocas líneas. Pero el centenario celebrado en el año 2017 ha vuelto a poner encima de la mesa algunas cuestiones que estaban olvidadas, ha profundizado en muchas otras y ha destapado nuevos ejes de investigación histórica. Muchas obras clave han sido reeditadas, algunas han sido rescatadas, otras han escrito partiendo de las fuentes primarias del acontecimiento. También ha habido grandes ausencias que merece la pena destacar.

En el presente texto se tratará de hacer un acercamiento a las aportaciones sobre el estudio de la Revolución rusa y también a sus carencias. Pero antes de entrar en materia conviene tener en cuenta algunas apreciaciones. Desde el mismo momento de su desarrollo, la Revolución rusa

1 Josep Fontana, El siglo de la Revolución. Una historia del mundo desde 1914 (Barcelona: Crítica, 2017), 11.

2 Moshe Lewin, El siglo soviético. ¿Qué sucedió realmente en la Unión Soviética? (Barcelona: Crítica, 2005).

DICTATORSHIPS \& DEMOCRACIES 6 (2018) · EISSN: 2564-8829 · PUNCTUM, UNIVERSITAT OBERTA DE CATALUNYA \& FUNDACIÓ CARLES PI I SUNYER 
levantó grandes pasiones y tuvo a la vez tanto fervientes defensores como furibundos detractores. Los que vivieron el acontecimiento plasmaron aquellas jornadas en sus reflexiones. Al calor inicial de ese acontecimiento se fueron asentando posteriormente todos los elementos historiográficos: desde historiadores marxistas ortodoxos que defendían sin fisuras toda la propaganda, hasta historiadores de la rama más conservadora que, partiendo de posiciones más políticas que historiográficas, se convertían en arietes contra el "peligro comunista". En medio quedaban los historiadores que realizaron trabajos de enorme interés para el estudio del acontecimiento, aunque fuera a veces con simpatías y otras con críticas. La caída de la URSS significó un repunte de la historiografía conservadora frente a la crisis del marxismo, en el que se presentó la Revolución rusa como el origen de todas las catástrofes que se habían originado en el mundo desde 1917. Sin embargo, el paso del tiempo y la apertura de los archivos soviéticos hicieron bascular los estudios, que se nutrieron de trabajos (comparativos, biográficos, de agentes poco conocidos, etc.) y que han desembocado en un rico centenario con aportaciones muy importantes.

Siguiendo a Arno J. Mayer y su estudio Las Furias. Violencia y terror en las revoluciones francesa y rusa, ${ }^{3}$ hay que decir que tanto la Revolución francesa como la rusa han seguido criterios de análisis muy similares. Los orígenes de la Revolución francesa se vieron jalonados tanto por sus partidarios, que hicieron historias en su defensa, como por los críticos, que — como Edmund Burke o el más reaccionario Joseph de Maistre - situaban la Revolución francesa como el origen de los males. Tiempo habría que pasar en los acontecimientos políticos franceses para que se empezase a defender nuevamente el concepto revolucionario francés, aunque con diferentes matices. Mientras Adolphe Thiers o Jules Michelet defendían el proceso liberal —en el caso del primero - y republicano —en el caso del segundo- y criticaban el jacobinismo como un accidente en el proceso revolucionario, personajes como Louis Blanc o más tarde Jean Jaurès defendían la posición de los jacobinos como una evolución del propio proceso. El centenario de la revolución sirvió para que el historiador

3 Arno J. Mayer, Las furias. Violencia y terror en las revoluciones francesa y rusa (Zaragoza: Servicio de Publicaciones de la Universidad de Zaragoza, 2013). 
François-Alphonse Aulard reivindicara la revolución y los girondinos, mientras que su alumno Albert Mathiez defendió la importancia de los jacobinos y de Robespierre tiempo después. La propia historiografía de la Revolución francesa se vio afectada por el estallido de la Revolución rusa, entre aquellos que veían a los bolcheviques como unos continuadores de los jacobinos y los que defendían el proceso revolucionario pero se desmarcaban de los bolcheviques. Mathiez fue la cabeza pensante más importante de aquel proceso. Con el ascenso de los fascismos y los totalitarismos, se comenzaron a mezclar los propios conceptos en las décadas de 1920 y 1930, entre los historiadores que desgajaban los distintos procesos o los que veían en la Revolución francesa y confirmaban en la rusa la deriva autoritaria y totalitaria de la sociedad. Como dice Arno J. Mayer:

En primer lugar, postularon la semejanza de las causas últimas y del funcionamiento del ascenso de la violencia de las Revoluciones francesa y rusa: se dijo que Robespierre, Rousseau y el Gran Terror eran prácticamente lo mismo que Lenin/Stalin, Marx y el GULAG. Interpretaron el terror jacobino a la luz del Terror bolchevique, y afirmaron que en el gobierno del miedo y sangre de 1793-1794 había el ensayo general y el presagio del gobierno de 1917-1918.

Su segundo paso consistió en estirar la analogía hasta abarcar el Tercer Reich. Se dijo que los regímenes soviéticos y nazis fueron en lo fundamental, cuando no en su totalidad, idénticos: ambos eran variantes del mismo totalitarismo, cuyas raíces filosóficas se remontaban al momento jacobino. ${ }^{4}$

A esta última cuestión contribuyeron los estudios de Hanna Arendt 5 desde un punto de vista sociológico y politológico. Y aunque la derrota nazi y fascista en la Segunda Guerra Mundial sirvió para resarcir a la URSS, lo cierto es que en el combate que iba a mantener en los años sucesivos con EEUU, la historiografía se vio seriamente afectada. En lo que respecta a la Revolución francesa, frente a la escuela marxista, que dio personajes de primer nivel como Albert Marius Soboul o Michel Vovelle, también hay que destacar a otros historiadores que, como François Godechot o Geor-

4 Ibídem, 13.

5 Hanna Arendt, Los orígenes del totalitarismo (Madrid: Alianza, 2006). 
ge Rudé, intentaron vincular la Revolución francesa a un proceso más amplio de revoluciones atlánticas. O bien a François Furet, que, desde un visceral anticomunismo y con una historia más opinativa que científica, marcó los ritmos de investigación e inauguró una historiografía conservadora que aún hoy se mantiene en obras como la de Mona Ozouf. Aunque la caída de la URSS marcó una crisis de la historiografía marxista, se han desarrollado nuevos proyectos de investigación alrededor de la Revolución francesa.

La razón de hacer esta síntesis sobre el proceso revolucionario francés es porque resulta fácil establecer un paralelismo con el ruso a la hora de analizar su evolución historiográfica. Se podrá comprobar cómo la transformación revolucionaria en Rusia marcó una serie de obras que analizaron el acontecimiento desde el mismo momento de su estallido. Los protagonistas y contemporáneos del mismo, como Trotsky, Rosa Luxemburg, John Reed, Jacques Sadoul, María Bochtkareva, Piotr Archinov, etc., ya escribieron sus memorias o libros en el mismo momento o reflexionaron años después sobre él. Asimismo, esa literatura del protagonista y del militante dio paso paulatinamente a una historia científica pero enmarcada en escuelas historiográficas que, tras la Segunda Guerra Mundial, se podrían resumir en el marxismo, el liberalismo-conservadurismo y el eclecticismo. Y finalmente, aunque nunca fue un acontecimiento que dejase de tener atención, el centenario ha provocado una ola de nuevas obras y la reedición de otras que ha puesto la Revolución rusa en primera línea de investigación historiográfica y ha permitido comprobar la importancia que tienen las visiones más negativas o críticas con el proceso revolucionario. Aun así, la escuela marxista ha planteado nuevos trabajos y han aparecido otros muchos de enorme interés. No es baladí, pues, este paralelismo con la Revolución francesa que tan bien ha visto Arno J. Mayer.

Por último, cabría hacer una consideración terminológica. El trabajo versa sobre la Revolución rusa, que, a tenor de la mayoría de los trabajos publicados, abarca un periodo de tiempo amplio que hunde sus raíces en el siglo xix y que estudia todo el desarrollo transformador hasta el estallido de 1917. Sobre el inicio del proceso hay debate. Algunos lo sitúan ya en el propio siglo xix y ponen el acento en movimientos como el decembrista de 1825 . Otros, a pesar de la importancia que conceden al siglo 
XIX, consideran la Revolución de 1905 como el origen más inmediato de la transformación revolucionaria y cuando comienzan a tomar cuerpo los agentes protagonistas de 1917. Otros, directamente, se centran en el año 1917 y todo lo restante lo consideran antecedentes. Por otro lado, la terminología "revolución rusa" es mucho más inclusiva que otras que se utilizan también con frecuencia. Ciertamente, se puede hablar de "revolución soviética", pero en tal caso el periodo se ceñiría a la aparición de los soviets en la Revolución de 1905 y solo se haría referencia a los grupos que defendían esas estructuras con los distintos matices. Los grupos opositores a los soviets, pero revolucionarios frente al poder zarista (como podían ser toda la suerte de liberales), quedarían fuera del análisis. Igualmente, hay quien habla de "revolución bolchevique", pero en tal caso se haría exclusiva mención al grupo triunfante del proceso y se dejaría fuera a todos aquellos que no lo apoyaron. Por ello la denominación "revolución rusa" es la que mejor abarca todas las categorías, grupos y protagonistas del proceso.

Como es de suponer, aquí se plantea un muestreo de algunas de las obras más importantes, así como de las líneas de investigación que abren. Abarcarlas todas es imposible en un espacio acotado.

\section{Los contemporáneos de la Revolución}

Uno de los pilares fundamentales de cualquier investigación histórica es ir a las fuentes directas del acontecimiento. Y estas no solo se localizan en los archivos y la prensa, sino que conocer el testimonio de sus protagonistas es fundamental para poder ensamblar muchas piezas de ese puzzle que es la historia. Sin embargo, estas memorias siempre hay que tomarlas con cautela, pues no dejan de ser las justificaciones de cada personaje ante el acontecimiento. La visión y la memoria personal de cada uno no son la historia en sí, sino un aspecto importante para ver el mosaico completo. La Revolución rusa fue rica en estas cuestiones y, aprovechando el centenario del proceso histórico, muchas de esas memorias se han vuelto a publicar, algunas con interesantes estudios previos.

Si partimos de la idea inicial de que la Revolución rusa es un proceso que hunde sus raíces en el siglo xIX, es importante valorar la visión que DICTATORSHIPS \& DEMOCRACIES 6 (2018) · EISSN: 2564-8829 · PUNCTUM, UNIVERSITAT OBERTA DE CATALUNYA \& FUNDACIÓ CARLES PI I SUNYER 
algunos revolucionarios dieron de aquellos acontecimientos. Rescatar movimientos como el nihilismo, el populismo u organizaciones como Narodnaïa Volia (La Voluntad del Pueblo) se convierte en parada obligatoria para ir viendo cómo se configuran los bloques políticos y sociales a comienzos del siglo xx. No hemos tenido la suerte de que obras como ¿Qué hacer? de Nicolai Chernyshevsky ${ }^{6}$ la rica obra de Alexander Herzen se reeditasen en el centenario de la revolución. De Herzen contamos con algunas obras reeditadas más recientemente como Crónica de un drama familiar $^{7}$ o Doctor Krupov, ${ }^{8}$ pero poco más.

Una de las memorias más interesantes que nos acercan a la historia de un grupo tan importante como Narodnaïa Volia son las de Vera Figner: Rusia en las tinieblas. Memorias de una nihilista. Las memorias de Figner son un perfecto anticipo de lo que supondrá, posteriormente, la Revolución de 1905 y la de 1917, y sitúan a la perfección los antecedentes del proceso. Además, la figura de Figner se convirtió en todo un símbolo para los revolucionarios rusos, ya que sobrevivió a todas las revoluciones y a la propia política represiva posterior a la revolución -falleció por causas naturales en 1942 en Moscú a los 89 años de edad-. Se vinculó a proyectos culturales como el Museo Kropotkin hasta su clausura en 1938, como ella misma explica:

Hoy, cuando las olas de la Revolución han vuelto a su cauce, trato de ser útil en el dominio cultural. Aparte de trabajos literarios y ayuda a las víctimas de nuestra guerra civil, actúo desde hace varios años como presidenta del Comité Kropotkin, que, a pesar de las desfavorables circunstancias, ha logrado fundar un bello Museo Kropotkin. Al mismo tiempo me esfuerzo por apoyar y desarrollar establecimientos de instrucción y centros culturales en el campo. ${ }^{9}$

Las memorias de Figner - que fueron traducidas al castellano en la década de 1930 por el polifacético, políglota y anarquista Valeriano Orobón

6 Nicolai Chernyshevsky, ¿Qué hacer? (Barcelona: Júcar, 1984).

7 Alexander Herzen, Crónica de un drama familiar (Barcelona: Alba, 2006).

8 Alexander Herzen, Doctor Krupov (Madrid: Ardicia, 2014).

9 Vera Figner, Rusia en las tinieblas. Memorias de una nihilista (Madrid: Zeus, s/a), 14. Existe una edición reciente de la obra en la editorial Antipersona del año 2016. 
Fernández-, cuentan la historia de esta interesante narodniki desde su nacimiento hasta inicios del siglo xx, dando especial importancia a todo lo relacionado con la organización Narodnaïa Volia así como al atentado que acabó con la vida del zar Alejandro II. A pesar de que posteriormente Figner ingresó en el Partido de los Socialistas Revolucionarios, su vinculación fue cada vez más modesta, aunque siempre fue un referente para los revolucionarios posteriores.

En la misma línea, y siguiendo un trazado cronológico, habría que destacar la obra de Boris Sávinkov Memorias de un terrorista,${ }^{10}$ donde cuenta de primera mano la estructuración y las actividades de la Organización de Combate del Partido Socialista Revolucionario (PSR). Las memorias de Sávinkov son importantes por varias razones. Por una parte, como protagonista de los acontecimientos, teje toda la tela de araña que significaba la organización revolucionaria durante las jornadas previas y posteriores a la Revolución de 1905 y remarca su complejidad: el PSR tenía una rama política y una rama armada que se complementaban en su combate emprendido contra el zarismo. Por otra parte, reconstruye la propia complejidad del lenguaje: la palabra "terrorista" no se entiende como algo peyorativo, sino como una forma de plasmar la ideología. Además, el propio Sávinkov nos lleva a vuela pluma por un periodo complejo en que el combate frontal contra el zarismo provocaba una reacción de este; asimismo, el autor refleja la enorme debilidad que en ocasiones tenía la Organización de Combate, ya que los infiltrados policiales hacían estragos en sus estructuras. Un elenco de nombres de primera línea como Víctor Chernov, Tatarov, Azev, etc., pululan por todo el libro. También se describen las importantes acciones que acabaron con la vida de alguno de los símbolos más importantes del zarismo, una contribución de sangre de gente muy joven y con formación, lo que indicaba también la composición social de estos grupos. Además, quien escribe las impresiones no era un personaje cualquiera, pues Sávinkov fue uno de los más destacados socialistas revolucionarios de primera hora, que con el paso del tiempo fue moderando su pensamiento hasta acabar participando en el gobierno de Kerensky. Sin embargo, no dejó nunca su faceta de conspirador, ya que se

10 Boris Sávinkov, Memorias de un terrorista (Barcelona: Dirección Única y La Cotali, 2017). 
le considera implicado en el atentado contra Lenin en 1918 al facilitar la pistola a Fanny Kaplan. Detenido y juzgado por las autoridades comunistas, fue condenado a muerte, pero se le conmutó la pena por todo lo que había representado en el pasado; en 1925 se suicidó o fue arrojado por una de las ventanas de la Lubianka, sede de la policía política. Lo cierto es que la importancia de Sávinkov fue tal que Albert Camus le dedicó una obra de teatro titulada Los justos. La obra de Sávinkov se conoció en España en 1931, cuando la editorial Cenit la publicó gracias a la traducción que realizó el dirigente comunista y periodista Andrés Nin.

Aunque estas memorias nos sirven para situar el contexto previo, es interesante acercarnos a la producción bibliográfica que dio la propia Revolución de 1917 de la mano de sus protagonistas o espectadores. Muchos fueron los protagonistas que escribieron sobre el acontecimiento, aunque destacaremos solo alguno de ellos, como León Trotsky, quien combina en Historia de la Revolución rusa ${ }^{11}$ la historia y la visión personal del protagonista de un proceso. Esta obra ha conocido numerosas ediciones $\mathrm{y}$, aunque concebida en tres tomos, recientemente se ha podido resumir en uno. Es una de las historias más completas del acontecimiento y tiene la característica de que Trotsky la comenzó a redactar apenas unas semanas después de la Revolución de Octubre de 1917. En la obra de Trotsky se pueden distinguir dos partes diferenciadas. La primera comprende hasta octubre de 1917, donde el autor que ha confraternizado con la propia masa revolucionaria muestra una imagen del momento histórico en conexión con los protagonistas anónimos de la revolución. Sin ir más lejos, Trotsky fue uno de los impulsores del primer soviet en San Petersburgo en las jornadas de 1905, así como uno de los posteriores dinamizadores de la misma estructura en el Petrogrado de 1917 a su regreso del exilio. Trotsky se marchó de Rusia siendo un marxista convencido, pero en la línea de un menchevismo revolucionario (mencheviques internacionalistas), y acabó uniéndose a las filas bolcheviques que habían adoptado gran parte del ideario que el propio Trotsky venía defendiendo en su periodo de exilio. En la segunda parte de la obra, Trotsky ofrece, tras la Revolución

11 León Trotsky, Historia de la revolución rusa, 3 vol. (Madrid: Sarpe, 1985). Recientemente ha sido publicada en un solo tomo por la editorial El Capitán Swing. 
de Octubre de 1917, el relato del gobernante, de quien se ha hecho con las estructuras del poder e intenta justificar las acciones que se están llevando a cabo. No fue una tarea fácil para un Trotsky como Comisario de Asuntos Exteriores, que le tocó negociar y firmar la Paz de Brest-Litovsk, que marcó el devenir de la división entre la izquierda revolucionaria; tampoco para el Trotsky creador del Ejército Rojo, que tuvo que emprender las acciones militares contra los opositores al gobierno soviético, pero también contra aquellos que no aceptaron el modelo revolucionario de los comunistas. La obra de Trotsky adquiere aún más importancia con el paso de los años, cuando en su disputa por el control del poder sale perdiendo frente a Stalin, lo que hizo que su historia de la revolución fuese proscrita en el interior de la URSS.

León Trotsky aúna en su obra la faceta del historiador y la memoria del protagonista siguiendo una tradición muy desarrollada en el movimiento obrero, si bien su Historia de la Revolución rusa tiene mucho componente autobiográfico. Algo que completó posteriormente con sus memorias tituladas Mi vida ${ }^{12}$ donde hace un repaso más general y no tan centrado en la Revolución de 1917 y sus consecuencias. A pesar de ello, el principal seguidor del trotskismo a la muerte del líder, Isaac Deutscher, decía lo siguiente sobre la labor de Trotsky como historiador:

No sería del todo correcto decir que, como historiador, Trotsky combinó el partidarismo extremo con la objetividad rigurosa. No le hacía falta combinarlos: ambas cosas eran el calor y la luz en su obra, y al igual que el calor y la luz estaban indisolublemente ligados. Él se mofó de la "imparcialidad” y de la "justicia conciliadora" del erudito que pretende subir a la muralla de una ciudad amenazada y hacerse oír al mismo tiempo por "los sitiadores y los sitiados". [....] Para el buen soldado nada es más importante que obtener una visión realista del "otro lado de la línea", una visión exenta de optimismo infundado y de emoción. Trotsky, el comandante de la insurrección de octubre, actuó so-

12 León Trotsky, Mi vida (Madrid: Tebas, 1978). 
bre la base de este principio; y Trotsky el historiador hace lo mismo. Logra en su imagen de la revolución la unidad de los elementos objetivos y subjetivos. ${ }^{13}$

A pesar de todos los inconvenientes, la visión de Trotsky acerca de la Revolución rusa es parada obligatoria para todos los estudios que se precien sobre el proceso.

Casi con el mismo nivel de datos, pero más crítico con la actuación de los bolcheviques, situaríamos la obra de Nikolai Nikolaevich Sukhanov La revolución rusa (1917) ${ }^{14}$ — no ha tenido reciente reedición en español y la que tenemos no es del todo fiable- Fue escrita en seis tomos por este revolucionario menchevique de la rama internacionalista. Aunque Sukhanov fue crítico con el régimen comunista, no fue hasta 1930 que se le detuvo por las críticas que profirió contra la política agraria de Stalin, viéndose inmerso en un juicio contra mencheviques que le costó el destierro, el exilio y la proscripción de su obra. Fuera de Rusia tuvo bastantes ediciones, si bien no es tan conocida como la anterior de Trotsky.

Un poco más modesto, al ser un análisis más político que histórico, fue el libro que publicó otra protagonista de los acontecimientos, aunque no estuviese en la misma Rusia. Nos referimos al libro de Rosa Luxemburg La revolución rusa.$^{15}$ El libro, publicado a título póstumo en 1921, son unas interesantes reflexiones de la revolucionaria alemana sobre el proceso ruso, fundamentalmente por dos cuestiones. La primera es que está escrito desde una perspectiva marxista, por lo que la crítica se ejerce desde la misma ideología que defendía a los triunfadores bolcheviques. La segunda es que el texto es un claro ejemplo de las luchas que existirán en el interior de la futura Komintern y los puntos centrales de la ruptura de las distintas tendencias dentro del marxismo. No hay que olvidar que este texto lo escribió Rosa Luxemburg tras el tratado de Brest-Litovsk, que marcó a nivel interior y exterior en Rusia un antes y un después. Lu-

13 Véase la conferencia de Manuel Aguilar Mora en la Universidad de Guanajuato el 29 de octubre de 2017: Trostky y su Historia de la revolución rusa, http://www.sinpermiso.info/textos/ trotsky-y-su-historia-de-la-revolucion-rusa.

14 Nikolai Nikolaevich Sukhanov, La revolución rusa (1917) (Barcelona: Luis de Caralt, 1970).

15 Rosa Luxemburg, La Revolución rusa (Barcelona: Anagrama, 1975). Existe una reedición reciente en la editorial Akal de 2017. 
xemburg fue muy crítica con esa decisión de los bolcheviques y también con otras relacionadas, por ejemplo, con la cuestión nacional, tema que separaba los pensamientos de Luxemburg y Lenin. ${ }^{16}$

Luxemburg, con una visión puramente marxista para analizar la Revolución rusa, a lo largo del libro afirma que los bolcheviques son una evolución natural de los revolucionarios de otras épocas. Fija una división entre la revolución democrático-burguesa de febrero y la socialista de octubre como evolución natural del propio proceso, haciendo una comparación con la revolución inglesa de 1688 y la francesa de 1789. Establece también una concepción dual de la revolución entre la posición reformista, que vincula a Kaledin, y la puramente revolucionaria, representada por los bolcheviques. ${ }^{17}$

Sin embargo, Rosa Luxemburg no concibió el libro para hacer una defensa a ultranza de un proceso, sino para plantear algunas contradicciones o errores que se estaban dando. Para Luxemburg la política agraria de Lenin fue escasa en relación con la que llevó a cabo en industrias, lo que provocó que los campesinos fueran más reacios a unirse a la revolución, de lo que infiere que fue campo abonado para otras tendencias revolucionarias o aun contrarrevolucionarias. Por otra parte, la cuestión nacional era nodal para Luxemburg. Mientras Lenin optó por una política de apoyo a las cuestiones nacionales como pilar fundamental del avance revolucionario, Luxemburg sacó la lectura contraria. Todas aquellas naciones que se independizaron, con el apoyo expreso de los bolcheviques, se pasaron al campo contrarrevolucionario, poniendo como ejemplo la Polonia de Josef Pilsudski o la Ucrania dividida entre proalemanes y nacionalistas de Petliura. Apuntaba también al error de los bolcheviques con la Asamblea Constituyente y al giro dictatorial que se había dado en Rusia, donde los derechos básicos habían sido cercenados para, incluso, las tendencias revolucionarias:

Pero la cuestión no se agota con la Asamblea Constituyente y el derecho electoral; no hemos considerado aún la abolición de las garantías democráticas 
más importantes para una vida pública sana y para la actividad política de las masas trabajadoras: libertad de prensa, de asociación y de reunión, que han sido denegadas para todos los adversarios del gobierno soviético. ${ }^{18}$

La crítica a los decretos y al poder del terror es para Rosa Luxemburg el asunto que puede derrotar a la Revolución rusa. Para la revolucionaria alemana, nacida en realidad en la ciudad de Zamosc (Polonia), el error de Lenin y Trotsky fue el mismo que el de Kautsky: confundir democracia con dictadura. Y hacerlo en un momento en que el bolchevismo tenía que encabezar y dinamizar un proceso revolucionario internacional. La vía que abrió Rosa Luxemburg fue la de la crítica a la Revolución rusa desde una concepción marxista.

Menos conocidas, pero no por ello menos interesantes, son las memorias que nos dejó Maria Leontievna Botchkareva, conocida como Yashka. Fue una de las mujeres que se unió a los batallones militares rusos durante la Primera Guerra Mundial y que formó parte del famoso Batallón de la Muerte, integrado por mujeres. ${ }^{19}$ Botchkareva, que durante la Guerra Civil primero se exilió y luego prestó ayuda a las tropas blancas de Kornilov y de Kolchak, fue finalmente detenida y ejecutada por la Cheká en 1920. Escribió unas memorias con el título Yashka. My Life as Peasant, Exile and Soldier, y recientemente se han publicado en castellano sus memorias sobre la participación en el Batallón de la Muerte con el título El batallón de mujeres de la muerte. ${ }^{20}$ En estas memorias se muestra una Botchkareva entre dos mundos: uno que se derrumba y del que ha formado parte y otro que nace y en el que no encaja. Aunque Botchkareva no vio con malos ojos el paso a una sociedad más liberal y democrática, tampoco era partidaria de la ruptura socialista y eso, unido a su mentalidad como militar, le llevó a unirse a las filas blancas durante la Guerra Civil rusa hasta el momento de su ejecución. Las memorias de Botchkareva son interesantes porque nos muestran la participación de la mujer en la Revolución

18 Ibídem, 73.

19 No hay que confundirlo con el Primer Batallón de Mujeres de Petrogrado, que fue quien defendió el Palacio de Invierno en el momento de producirse la Revolución de Octubre de 1917.

20 Maria Botchkareva, El Batallón de Mujeres de la Muerte (Madrid / Barcelona / Buenos Aires: Mundo Latino, 1930). Hay una edición reciente basada en esta, publicada por la editorial El Desvelo en 2016. 
rusa, algo que podemos completar en esta línea de investigación con las obras de revolucionarias como Alexandra Mijailovna Kollontai, Nadezhda Konstantínovna Krúspkaia o Emma Goldman, que sí participaron en el proceso revolucionario socialista. Se trata de una línea de investigación que, desgraciadamente, no se ha tenido tan presente.

Sin ser estrictamente política y también escrita por una mujer, destacaríamos la obra de la poetisa Marina Tsvietáieva Diarios de la Revolución de $1917 .{ }^{21}$ Es una obra apenas conocida, de una poetisa también poco conocida, que ofrece una visión intimista y literaria de la atmósfera que se vivía en Rusia en las jornadas de 1917. Un libro ignoto que rescata la figura de Tsvietáieva, que se tuvo que exiliar en 1922, aunque regresó a Rusia en 1939 junto a su marido, que trabajaba entonces para el contraespionaje soviético de la NKVD. Con la ocupación nazi y la ejecución de su marido por la NKVD, la autora del libro acabó suicidándose en 1941. A pesar de que su poesía estaba proscrita en Rusia, fue rehabilitada como autora en 1955 durante el proceso de desestalinización.

Del mismo modo que la Revolución rusa desató en el momento histórico un análisis de sus protagonistas y fue, junto con la Comuna de París de 1871, uno de los primeros ejemplos de participación de la mujer en las transformaciones revolucionarias, también generó un extremado interés por parte de los extranjeros que estaban ya en Rusia o que acudieron allí llamados por el movimiento revolucionario, para verlo in situ o, incluso, unirse a sus filas. Y aunque fueron muchos los extranjeros que dejaron su impronta sobre la revolución, hay dos autores cuyas obras han tenido una mayor trascendencia: el norteamericano John Reed y el francés Jacques Sadoul, ambos partidarios y defensores de los bolcheviques.

Quizá la obra más importante es la de John Reed y sus Diez días que estremecieron el mundo, ${ }^{22}$ parada obligatoria para analizar la Revolución rusa de 1917. El periodista Reed no llegaba de nuevas a Rusia, pues ya tenía un bagaje importante de participación política y sindical en EEUU, y había sido testigo de la Revolución mexicana de 1910. Integrante del Par-

21 Marina Tsvietáieva, Diarios de la Revolución de 1917 (Barcelona: Acantilado, 2015).

22 John Reed, Diez días que estremecieron el mundo (Barcelona: Akal, 1998). Han aparecido recientes ediciones en 2017 en las editoriales Arpegio, Renacimiento o Txalaparta. 
tido Socialista de EEUU y amigo de revolucionarias como Emma Goldman, con la que participó en el interior de la IWW (Industries Workers of the World), cuando comenzó el movimiento revolucionario en Rusia se trasladó a Petrogrado; poco después se unieron su compañera sentimental Louise Bryant y el también periodista y socialista Albert Rhys William. El libro de Reed - que fue llevado al cine por Warren Beaty en la película Rojos - son sus impresiones personales y el análisis del momento histórico que le tocó vivir. Pero lejos de una visión del periodismo equidistante, Reed se vinculó con las masas, visitó las fábricas, participó de las manifestaciones y de los mítines, conoció a los principales dirigentes revolucionarios y plasmó con realismo la atmósfera que él mismo vivió, hasta unirse sinceramente a las filas comunistas. Los cuadros que Reed nos ofrece en su libro respecto a lo que se vivía en Petrogrado mostraban la realidad de esa dualidad de poderes que se vivía en Rusia. La efervescencia revolucionaria la plasmaba así Reed en su libro: «Qué asombroso espectáculo ofrece la fábrica Putilov cuando de sus muros salen en compacto torrente cuarenta mil obreros para oír a los socialdemócratas, eseristas, anarquistas, a quien sea, hable de lo que hable y por mucho tiempo que hable!»». ${ }^{23}$ Además, Reed, que venía de la experiencia americana donde el movimiento anarquista también tenía mucha fuerza, concedió en su obra mucha importancia a la diversidad de grupos políticos que dinamizaron la Revolución de 1917, aunque mostrase un mayor interés hacia los bolcheviques. John Reed no solo se unió a las filas comunistas, sino que fue el primer extranjero enterrado en los muros del Kremlim a su fallecimiento el 17 de octubre de 1920. Su figura trascendió a la propia revolución y sus escritos se han convertido en un clásico mundial sobre la Revolución rusa de 1917 .

Por otro lado, destacamos las impresiones que el francés Jacques Sadoul puso por escrito en pleno proceso revolucionario, menos conocidas, pero no por ello menos importantes. Sadoul, en el momento de la revolución, era un oficial del ejército francés establecido en Rusia, que, debido al contacto que mantuvo con los bolcheviques, adquirió sus ideas y defendió su causa. No venía de vacío de Francia, pues Sadoul pertenecía a la SFIO y es-

23 Reed, Diez dias que estremecieron el mundo, 43. 
taba vinculado al movimiento obrero socialista francés, seguidor del ideario de Jean Jaurès. A Sadoul le unía una gran amistad y compañerismo con Albert Thomas, una de las figuras más representativas del socialismo del momento, que llegó a ser ministro de Armamento y que nombró a Sadoul adjunto de Estado de Artillería. Cuando en 1917 los socialistas franceses salen del gobierno, Sadoul consigue que el nuevo ministro, Louis Loucher, lo destine en misión militar francesa a Petrogrado.

El libro Cartas desde la revolución bolchevique ${ }^{24}$ es la recopilación de la correspondencia que Sadoul enviaba a Albert Thomas para ponerle al día de los sucesos de Rusia. Poco a poco, Sadoul se iba convirtiendo en una referencia para los bolcheviques rusos, se entrevistaba con sus principales líderes, tomaba amistad con muchos de ellos, sobre todo con Trotsky, e iba adoptando el ideario que defendían. Estamos ante el momento del paso del Sadoul socialista al Sadoul comunista. La importancia de este epistolario la marca Constantino Bértolo, compilador de la obra y autor del prólogo:

Sobre su condición de libro indispensable para entender muchas de las claves de la revolución soviética, no cabe sino señalar que frente a la inmensa cantidad de publicaciones que informan, juzgan e interpretan, desde fuera, lo que sucedió, las notas de Sadoul informan, juzgan e interpretan, desde dentro, lo que está sucediendo. Los escritos de Sadoul no son Historia, están escritos por la Historia. ${ }^{25}$

El volumen no solo recopila las epístolas que mantuvo Sadoul con Thomas, sino que también rescata la correspondencia que mantuvo con escritores de la época comprometidos con las causas sociales como fueron Henri Barbusse o Romain Rolland. Lo que se extrae de las cartas es que Sadoul defendió las políticas bolcheviques frente a los representantes de su propio gobierno, así como que los bolcheviques vieron en Sadoul un aliado y alguien con el que seguir teniendo un contacto, en medio de la Guerra Civil, con las fuerzas aliadas. El texto de Sadoul nos abre las puertas a cuestiones como el cordón sanitario que se formó alrededor de la

24 Jacques Sadoul, Cartas desde la revolución bolchevique (Madrid: Turner, 2016).

25 Ibídem, 9. 
Rusia revolucionaria, las actividades de las fuerzas aliadas contra el avance del comunismo y el interés que despertó todo el proceso revolucionario.

Para cerrar esta parte - que sería inabarcable en caso de tocar todas las obras-, cabe hablar, siguiendo un poco la línea marcada por Rosa Luxemburg, de personajes como Víctor Serge o de los anarquistas Vsevolod Mijailovich Eichembaum "Volin" y Piotr Andreievich Archinov.

El caso de Víctor Serge - cuyo nombre real era Víctor Lvovich Kibálchich- es interesante por ser uno de los protagonistas de la revolución, formar parte del aparato del poder bolchevique y pasar luego al exilio por oponerse a la dictadura estalinista. Nacido en el exilio, sus inicios políticos se sitúan primero en el populismo ruso y posteriormente en el anarquismo, con el que siempre tuvo mucha vinculación, formándose como tal en grupos franceses y visitando España, lo que le convirtió también en un referente para los españoles. Condenado por su vinculación a la Banda de Bonnot, estuvo un tiempo en cárcel, viajó a Rusia, se unió a las filas bolcheviques y trabajó en el interior de la Komintern junto a Zinoviev. Aunque defendió los postulados bolcheviques, fue muy crítico con ellos en aspectos como la represión contra el anarquismo ruso. Partidario de la oposición de izquierdas de Trotsky, Serge se enfrentó a Stalin y eso le valió su purga y exilio, primero a Francia y posteriormente a México, donde falleció en 1947.

La producción literaria de Serge es amplia y parte de ella se sitúa en el mismo momento de la revolución. Habría que destacar obras como Mémoires d'un révolutionnaire, ${ }^{26}$ donde hace un repaso a su vida personal y su evolución ideológica, con un lenguaje con mucha soltura y un elenco de personajes que marcan la historia del movimiento obrero internacional. Además, el hecho de que Serge estuviese en varios grupos hace de su obra un acercamiento a una realidad de amplios horizontes, pues mantuvo buenas relaciones con antiguos compañeros suyos. Con El año I de la Revolución rusa, ${ }^{27}$ nos encontramos ante un texto clásico, escrito y editado ya en España en la década de 1930, y que pasa por ser uno de los

26 Víctor Serge, Mémoires d’un révolutionnaire (París: Seuil, 1978). Existe una edición reciente en castellano en la editorial Veintisiete Letras del año 2011.

27 Víctor Serge, El año I de la Revolución rusa (Buenos Aires: RYR, 2011). Existe una edición reciente en la editorial Traficantes de Sueños de 2017. 
relatos más pormenorizados del inicio de la revolución y del desarrollo de las ideas leninistas. En esta misma línea cabría citar El destino de una revolución. ${ }^{28}$ Sin embargo, la importancia de Serge radica en que no solo utilizó la historia para hacer sus análisis o denuncias, pues también lo hizo a través de la novela. El terror rojo que se produce durante la Guerra Civil y que llevó a numerosos revolucionarios a ser ejecutados se plantea en su novela Ciudad conquistada, ${ }^{29}$ mientras que el terror estalinista lo aborda en textos como Medianoche en el siglo ${ }^{30}$ o El caso Tulayev. ${ }^{31}$ Serge introduce muchas temáticas y vías de investigación posteriores, como la deriva represiva de los bolcheviques o las purgas que se produjeron dentro del partido con el ascenso del estalinismo. Pero lo interesante de Serge es que él mismo es una vía de investigación por lo que representa para el desarrollo y la lectura de la Revolución rusa.

Por último, habría que destacar la visión de los protagonistas de la revolución que salieron derrotados del proceso revolucionario, aunque muchos de estos escritos tienen ediciones muy antiguas y son casi desconocidos o ni siquiera están publicados. Cabría aquí citar la obra de Boris Fiodorovich Sokolov, diputado de la Asamblea Constituyente, titulada Los bolchevikes juzgados por ellos mismos. Documentos de los soviets de 1919, ${ }^{32}$ donde realiza una crítica como eserista al poder ejercido por los bolcheviques. Un texto de época que no se volvió a reeditar posteriormente.

Algo más de suerte tuvieron los anarquistas Volin y Archinov, que con sus obras mostraron la participación anarquista en la Revolución rusa. Ambos personajes, aunque protagonistas de la revolución, escribieron sus reflexiones tiempo después, cuando ya estaban exiliados. En La revolución desconocida ${ }^{33}$ Volin hace un repaso a la formación y el desarrollo

28 Víctor Serge, El destino de una revolución (Barcelona: Libros de la Frontera, 2011).

29 Víctor Serge, Ciudad conquistada (Barcelona: Página Indómita, 2017).

30 Víctor Serge, Medianoche en el siglo (Madrid: Alianza, 2016).

31 Víctor Serge, El caso Tulayev (Madrid: Capitán Swing, 2013). La editorial Alfaguara tiene una edición de 2007.

32 Boris Sokolov, Los bolchevikes juzgados por ellos mismo. Documentos de los soviets de 1919 (Madrid: Juan Pueyo, 1920).

33 Volin, La revolución desconocida (1917-1921). Documentación inédita sobre la revolución rusa, 2 vol. (Madrid: Campo Abierto, 1977). Existe una edición en un volumen, del mismo año, en la editorial Proyección. 
de los movimientos revolucionarios rusos desde el siglo xix hasta la participación de los anarquistas en la Revolución de 1905 y en la de 1917. El libro de Volin, aun siendo justificativo para sus principios, aporta algunas cuestiones de verdadero interés. Cercano a las filas de los socialistas revolucionarios en 1905, Volin cuenta cómo surgió el primer soviet durante la Revolución de 1905, en un ambiente íntimo y del que él mismo fue testigo. Fue en su propia casa y con Nossar presente. ${ }^{34}$ Este dato novedoso viene a engrosar el debate que se establece sobre el nacimiento del soviet y que tan bien estudió en la década de 1970 Oskar Anweiler. ${ }^{35}$ Pero Volin no solo recupera debates y documentos del momento, en los que él mismo participó, sino que hace un análisis del carácter autoritario del Estado soviético desde una perspectiva anarquista, y habla de dos acontecimientos nodales para la historia del propio anarquismo ruso como fueron el majnovismo en Ucrania o la revuelta de los marinos de Kronstadt en 1921. Un clásico en toda regla de la historia del anarquismo ruso que ha sido reimpreso en muchas ocasiones, pero que no dispone de una edición nueva y crítica.

El otro libro que queremos destacar es Historia del movimiento majno$v i s t a,{ }^{36}$ donde Piotr Archinov estudia el movimiento campesino de Néstor Majnó en Ucrania. Archinov, que había empezado en las filas bolcheviques, se pasó al anarquismo tras la Revolución de 1905 y se unió desde muy pronto a la guerrilla majnovista, a la que historió in situ; perdió en varias ocasiones el manuscrito y lo rehizo para finalmente publicarlo en el exilio. Tras los debates que se dieron en el anarquismo ruso exiliado, en los que Archinov quedó en minoría en su intento de articular una plataforma de anarquistas, se volvió a retractar de sus principios libertarios y regresó a la URSS donde se unió al Partido Comunista y desapareció en la represión estalinista. En este libro, Archinov repasa de forma pormenorizada, y en ocasiones en forma de epopeya, la lucha del majnovismo contra todos aquellos que se opusieron a su modelo revolucionario y que finalmente fueron aniquilados por el gobierno bolchevique. Este libro, a

34 Ibídem, 58-63.

35 Oskar Anweiler, Los soviets en Rusia (Bilbao: Zero ZYX, 1975).

36 Piotr Archinov, Historia del movimiento macknovista (Barcelona: Tusquets, 1975). Hay una edición más reciente de la editorial LaMalastesta de 2012. 
caballo entre la historia y la memoria, se podría completar con las memorias escritas por el protagonista del movimiento, Néstor Ivánovich Majnó, que no han sido traducidas al castellano, como tampoco las de su lugarteniente Víctor Belash, ambas disponibles en ruso.

Las obras de Volin y Archinov —así como las otras citadas aunque no estén traducidas - marcan la pauta de investigación del anarquismo en la Revolución rusa a partir de sus protagonistas, un fenómeno apenas conocido en la historia.

\section{Los clásicos nunca mueren}

El periodo que media entre el asentamiento de los comunistas en el poder y la caída de la Unión Soviética en 1991 generó una forma de entender la historia de la Revolución rusa que estuvo bajo la égida, en primer lugar, del ascenso de los fascismos y de la crisis del periodo de entreguerras y, en segundo lugar, de la Guerra Fría, que enfrentó a las dos superpotencias, EEUU y la URSS. Hubo una amplia producción bibliográfica a ambos lados del muro que iba desde la hagiografía revolucionaria que se daba en la URSS hasta las críticas sin fundamento en Occidente, en la mayoría de las ocasiones con un peso más político que historiográfico y con la historia como punta de lanza en el combate de las superpotencias.

A pesar de ello, durante este tiempo surgieron una serie de textos que fueron de interés y que formaron una concepción de cómo se tenía que tratar el acontecimiento. En ese momento, la historiografía, por el modo de enfoque y de estudio que se daba al proceso revolucionario, se podría calificar de conservadora o de marxista, con todos los matices que ello conlleva. Porque la historiografía marxista no fue solo la hagiografía, sino que hubo interesantes obras de investigación sobre el fenómeno. Y la historiografía conservadora, mucho más poderosa en aquellos momentos en Occidente, no fue exclusivamente de carácter político. También hubo obras de difícil catalogación, que se ubican en el eclecticismo historiográfico.

Podríamos destacar, en un primer bloque, a personajes que intentaron articular un discurso histórico alrededor de la revolución, pero la carga negativa que le confieren los aleja, en muchos puntos, de una concepción científica de la historia. Además, alguno de esos personajes hizo un 
camino político que determinaría su visión, si bien hay cuestiones que pueden ser de ayuda a la hora de iniciar un estudio sobre la Revolución rusa. Aquí se sitúan los trabajos del periodista William Henry Chamberlin: en un principio seguidor de los ideales comunistas y defensor de los bolcheviques, posteriormente dio un giro a su pensamiento y realizó en la década de 1930 trabajos comparativos entre el fascismo y el comunismo y escribió desde una posición anticomunista. En 1935 publicó su obra The Russian Revolution: 1917-1921,37 que no conoce traducción en castellano, y en la que hace una crítica desde un punto de vista más ideológico que histórico de la Revolución de 1917 y de sus consecuencias. Sin embargo, el hecho de haber sido parte de los comunistas y de haber mostrado mucho interés por la historia de Rusia hace que su obra tenga partes rescatables.

En una línea muy similar, pero ya en periodo de Guerra Fría, se sitúa la obra de George F. Kennan, famoso por el telegrama enviado desde Moscú en 1946 al presidente Truman y considerado el padre de la "política de contención al comunismo”. Kennan, junto a su carrera diplomática y política, desarrolló una intensa actividad como historiador, especializándose en la historia rusa, a la que dedicó varias páginas. Cabría destacar aquí Russia Leaves the War,,$^{38}$ un análisis del Petrogrado de la revolución a través de los documentos de la embajada norteamericana. Partiendo de figuras biográficas, sobresale Russia and the West under Lenin and Stalin, ${ }^{39}$ una obra muy crítica con el desarrollo soviético en un contexto de Guerra Fría. No es exclusivo de Kennan unir carrera política con conocimiento de Rusia y comunismo. Más recientemente, la exsecretaria de Estado del gobierno de George W. Bush, Condoleezza Rice, publicó diversos trabajos sobre el mundo soviético.

Volviendo al periodo de Guerra Fría, aparecieron algunas obras escritas por periodistas y aficionados a la historia como Alan Moorehead, que desde una posición conservadora realizó un volumen extenso sobre la historia de la Revolución rusa. Siguiendo la estela de Chamberlin, Moorehead

37 William Henry Chamberlin, The Russian Revolution: 1917-1921 (Nueva Jersey: Princeton University Press, 1987).

38 George F. Kennan, Russia Leaves the War (Nueva Jersey: Princeton University Press, 1956).

39 George F. Kennan, Russia and the West Under Lenin and Stalin (Boston: Little, Brown and Company, 1961).

DICTATORSHIPS \& DEMOCRACIES 6 (2018) · EISSN: 2564-8829 · PUNCTUM, UNIVERSITAT OBERTA DE CATALUNYA \& FUNDACIÓ CARLES PI I SUNYER 
vinculó el ascenso del nazismo a la propia Revolución rusa e, incluso, el estallido de la Segunda Guerra Mundial: «La elevación de los nacis [sic] al poder en Alemania estuvo íntimamente ligada con la herencia que dejó Lenin; y sin las seguridades de ayudarle que dio Stalin a Hitler, éste no se habría atrevido a hundir al mundo en otro espantoso conflicto bélico.» ${ }^{40}$ Reconociendo que la obra la realizó por encargo, ya que Moorehead había destacado hasta ese momento en cuestiones relacionadas con África y el Mediterráneo, la carga peyorativa de la revolución es un tema recurrente a lo largo de todo el texto. Y como él mismo reconoció, no hizo un trabajo de archivo sino que se basó solo en bibliografía. Moorehead compara constante el zarismo y lo que vino posteriormente, algo que continuarán en el futuro otros autores; hace un repaso completo a la revolución desde el siglo XIx hasta Brest-Litovsk, y establece, desde una posición más subjetiva que histórica, algunos axiomas que posteriormente nutrirán la historiografía conservadora de la Revolución rusa.

El campo marxista tuvo en este momento escritores e historiadores de primer nivel que introdujeron aspectos de gran importancia para el avance de los estudios de la Revolución rusa. Dejando a un lado los trabajos hagiográficos que surgieron - con mayor o menor importancia- en los años de existencia de la URSS, cabría destacar en un primer momento al periodista y ensayista Bertram Wolfe. Norteamericano de origen alemán, pasó a la historia por participar en la creación del Partido Comunista de EEUU y del Partido Comunista de México, y por ser el biógrafo oficial del pintor, también comunista, Diego Rivera. De entre su magna obra relacionada con el periodo soviético, habría que destacar Three Who Made a Revolution, ${ }^{41}$ escrita en 1948, donde Wolfe diserta sobre la biografía de Lenin, Trotsky y Stalin, y establece el protagonismo de los personajes en el momento histórico. Junto a anotaciones que Wolfe realizó en obras relacionadas con Rusia, también intervino en la cuestión de los juicios de Moscú, en los que, si en un principio dio credibilidad a la versión oficial estalinista, un estudio más detenido le hizo cambiar de opinión sobre las

40 Alan Moorehead, La revolución rusa (Barcelona: Destino, 1958), 7.

41 Bertram Wolfe, Three Who Made a Revolution. A Biographical History (Washington: Dial Press, 1948). Existe una edición en castellano del año 1956 editada por José Janés. 
acusaciones que se vertieron contra Trotsky. Aquí pudo influir el posible contacto entre el líder revolucionario ruso y el norteamericano durante la estancia de Trotsky en México hasta su asesinato en 1940. A pesar de ello, la historia de Wolfe no deja de tener una importante carga ideológica que vendrían a corregir sucesivos historiadores del campo marxista.

Quizá el historiador marxista más afamado de este periodo que realizó un trabajo sobre la Revolución rusa fue Christopher Hill, miembro del grupo de historiadores del Partido Comunista de Gran Bretaña y participante de proyectos académicos de enorme trascendencia como Marxism Today o Our History. Junto a él destacaron una generación de brillantes historiadores, entre los que se encuentran personajes de la talla de Vera Gordon Childe, Eric J. Hobsbawn o E.P. Thompson, que marcaron una metodología de investigación aún hoy en vigencia. El caso de Hill es más llamativo al ser un reputado modernista, especialista en la Revolución inglesa del siglo XVII, que hizo una brillante incursión en el fenómeno de la Revolución rusa a través de una historia breve pero que ya es un clásico de referencia. Hill, haciendo gala de un materialismo histórico apegado al análisis - y nunca como una teoría de la historia - , realizó un trabajo sencillo, dividido en antecedentes de la revolución - confiere el protagonismo revolucionario a Lenin-, desarrollo y consecuencias de esta. A pesar de ello, Hill no entra en los análisis pormenorizados de las diferentes tendencias revolucionarias; tan solo hace una comparación entre la fuerza y eficacia bolcheviques frente a la ineficiencia menchevique. Para Hill hay una consecuencia fundamental en el proceso soviético: desarrollar, por una parte, la importancia que dicha revolución ha tenido para muchos lugares del planeta, aunque no en todos se hayan podido implementar unas estructuras mucho más propias de un país como Rusia; explicar, por otra parte, cómo ese mismo sistema tiene una influencia sobre Occidente, no para implementar medidas similares sino para contener otras. ${ }^{42}$ Por último, Hill destaca que la gran lección de la Revolución rusa es la posibilidad y viabilidad de la conquista del poder por parte de los humildes, que han demostrado que pueden llevar las riendas del poder

42 Christopher Hill, La Revolución rusa (Barcelona: Ariel, 1985), 212. La misma editorial editó una nueva edición de la obra en 2017. 
político con mejor capacidad que otros. Y para él esto lo ha evidenciado la URSS en su victoria sobre los nazis en la Segunda Guerra Mundial. ${ }^{43}$ Con este breve trabajo, que cumple todos los criterios de una historiografía marxista seria, Hill legó a la posteridad una obra clásica. Es una parada imprescindible para los estudios de la Revolución, aunque, con el paso del tiempo, ha sido superada por otras investigaciones.

En este campo marxista cabría destacar, por último, la figura del historiador Pierre Broué y sus importantes estudios sobre el bolchevismo y el comunismo en Rusia. El objetivo de las obras de Broué fue, desde el primer momento, mostrar que la idea original de la revolución legada por Lenin y Trotsky nada tenía que ver con lo sucedido a partir de 1924 con la llegada de Stalin al poder. Broué, que además de historiador era un militante trotskista, realizó trabajos de investigación rigurosos a partir de bibliografía y de documentos de primera mano de exiliados por el estalinismo o que podía haber adquirido a través de la compra. Su primera gran obra en esta línea la publicó en 1963 con el título Le parti bolchevique. Histoire du PC de l'URSS. ${ }^{44}$ En ella Broué realizó un profundo trabajo sobre el origen, el desarrollo y las derivas de los bolcheviques, convirtiéndose en la más afamada obra de la historia del partido no oficial. Con ese fuerte componente trotskista, su aparición no fue baladí el 1963, años después del inicio de la desestalinización dirigida por Jruschov y antes de la crisis que se desataría en el interior del PCUS con la destitución de Jruschov y la llegada de Brezhnev. Además, en ese tiempo se había producido la crisis del comunismo internacional representada por la revuelta en Hungría dirigida por Imre Nagy. La edición en castellano apareció tras la crisis de 1968 y la invasión de Checoslovaquia por las tropas del Pacto de Varsovia contra el socialismo de rostro humano de Dubcek. Esta obra de Broué es una de las más completas, pues el autor francés es quien mejor distingue los límites entre grupos políticos en la Rusia prerrevolucionaria y revolucionaria, así como los debates internos entre ellos. La explicación del concepto de "democracia soviética" y las difíciles relaciones entre bol-

43 Ibídem, 212-213.

44 Pierre Broué, Le parti bolchevique. Histoire du PC de l'URSS (París: Les Éditions de Minuit, 1963). Existe una edición en castellano editada por Ayuso en 1974. 
cheviques, socialistas revolucionarios de izquierda y anarquistas tienen en Broué una parada obligatoria. Igualmente, los debates generados en el interior del bolchevismo entre las tendencias representadas por Zinoviev, Bujarin, Preobrazhensky, Piatakov, Trotsky, Stalin, etc., son perfectamente planteados por el historiador francés, lo que le convierte en una línea de investigación utilizada con posterioridad. Además, lo importante de la obra de Broué es la unión de los sucesos rusos con la política internacional, relacionando todo y haciendo un plano completo de la situación del momento. Con todo ello Broué dejó muy claro el problema que tuvo con las fuentes y la dificultad de acceso a las mismas en el momento de escribir la obra:

A este respecto resulta además altamente significativo el hecho de que la trama básica de condiciones de investigación acerca de la Unión Soviética, desde la Revolución de Octubre de 1917 hasta nuestros días, tanto desde el punto de vista de la publicación de documentos como desde el de la mera historiografía, se articula de forma perfectamente natural en torno a las fechas que suponen decisivos virajes en la historia política del país. Así, 1924 supone la muerte de Lenin, pero también el enunciado de las premisas de lo que sería la dictadura estaliniana y 1956 marca el principio de la denuncia del "culto a la personalidad" de Stalin a cargo de sus lugartenientes de ayer convertidos en sus sucesores. ${ }^{45}$

Debido sobre todo a su militancia trotskista, Broué no solo se quedó en el análisis del Partido Bolchevique y su evolución a PCUS, sino que puso especial atención a elementos como los juicios de Moscú, ${ }^{46}$ el desarrollo de la Komintern ${ }^{47}$ - pudo acceder a los archivos soviéticos tras la caída de la URSS en 1991- o la represión estalinista. ${ }^{48}$ Broué pasa por ser uno de lo conocedores más exhaustivos de las disputas internas de los bolcheviques en el periodo revolucionario y posterior. También son importantes sus

45 Pierre Broué, El Partido Bolchevique (Madrid: Ayuso, 1974), 23.

46 Pierre Broué, Los procesos de Moscú (Barcelona: Anagrama, 1964). Existe una segunda edición de 1988.

47 Pierre Broué, Histoire de l'International Communiste, 1919-1945 (París: Fayard, 1997).

48 Pierre Broué, Communiste contre Staline. Massacre d’une génération (París: Fayard, 2003). Existe una edición en castellano, por la editorial Sepha, de 2008. 
incursiones en cuestiones de la Guerra Civil española y de la revuelta de Hungría y Alemania.

De esta época, y a caballo entre una visión marxista y anarquista, se sitúa la obra de Maurice Brinton Los bolcheviques y el control obrero, ${ }^{49}$ donde se analizan las difíciles relaciones entre el control estatal y el control obrero de la producción en un estudio cronológico de la revolución durante los cuatro años que median entre 1917 y 1921. Es una obra que ha pasado completamente desapercibida en el año del centenario y que contiene elementos de mucho interés.

Si nos centramos en la idea del trabajo desarrollado por la historiografía británica en relación con la Revolución rusa, la obra más completa, trabajada y analizada es la de Edward Hallett Carr, que pasa por ser el mejor conocedor del mundo soviético y comunista en el periodo de la Guerra Fría. Varias son las obras que escribió Carr al respecto y cuya lectura sirvió como arranque para muchas investigaciones posteriores. Dice Broué en este sentido:

Comparada con la historiografía soviética, la anglo-sajona ilumina ampliamente la etapa que nos ocupa. Ciertamente dispone de muchos menos materiales de primera mano, pero en cambio se beneficia de una gran flexibilidad en la organización de sus tareas. [...] En general la información que sustentan las obras de estos historiadores es de una solidez a toda prueba y aun en nuestros días es considerada como un caudal enormemente valioso por el propio investigador o estudiante soviético que no ha tenido este material a su disposición. [...] Este es el caso sobre todo de la obra de Edward Hallett Carr, su monumental Historia de la Rusia Soviética, cuyos siete primeros volúmenes han sido publicados..$^{50}$

La vida investigadora de Carr estuvo en su casi totalidad entregada al estudio de Rusia, aunque también es autor de importantes obras sobre el concepto de la historia, que se resume, tal como indicaba Broué, en su Historia

49 Maurice Brinton, Los bolcheviques y el control obrero, 1917-1921. El Estado y la contrarrevolución (París: Ruedo Ibérico, 1972).

50 Broué, El Partido Bolchevique, 26-27. 
de la Rusia Soviética, dividida en cuatro tomos: La revolución bolchevique, 1917-1923; El interregno, 1923-1924; El socialismo en un solo pais, 19241926, y Las bases de una economía planificada, 1926-1929. ${ }^{.1}$ Además, E.H. Carr completó estos estudios con otros parciales dedicados a biografías como la de Bakunin o Dostoyevski, cuestiones de la Internacional comunista, relaciones internacionales, etc. Carr fue el más reputado estudioso del mundo soviético y en él se detienen innumerables obras para hablar sobre este tema. Al igual que Broué, pero sin un componente ideológico tan marcado y más ubicado en una historiografía académica y ecléctica, los aspectos que Carr analiza en sus obras son novedosos y rompen con las visiones convencionales o excesivamente lineales de la Revolución rusa. La obra de Carr fue editada en castellano, y en ella podemos apreciar el grado de erudición del historiador y los datos que aporta al proceso. Una de las novedades que introduce Carr es, por ejemplo, la importancia que concede a organismos como los soviets, entendidos como entidades de poder obrero que se desarrollan a partir de la Revolución de 1905. Dando un paso más, es Carr quien va a establecer el debate que se entabla alrededor del soviet y que pone como protagonistas a figuras como Nossar-Jrustalev, primer presidente del soviet de San Petersburgo. Aquí la obra de Carr se vio reforzada por el estudio sobre los soviets que hizo Oskar Anweiler, que hemos reseñado más arriba. Pero también analiza cuestiones como la reunión que tuvieron Lenin y Sverdlov con el líder campesino y anarquista Néstor Majnó en 1918, cuestión apenas tratada en la historia y que pasa desapercibida a no ser que se lean las memorias del propio Majnó. ${ }^{22}$ Sus estudios sobre las cuestiones económicas y el paso de la internacionalización de la revolución a la revolución en un solo país de Stalin, marca una de las líneas de investigación trabajadas con posteridad.

Por otro lado, Carr es un historiador sensible con la idea de hacer comprender los procesos históricos a un mayor número de personas. Su Historia de la Rusia Soviética no deja de ser una obra de carácter erudito y académico. Sin embargo, Carr se planteó la necesidad de que la historia de la Revolución rusa, de la evolución del bolchevismo y de sus líderes fuese

51 Edward Hallett Carr, Historia de la Rusia soviética, 4 tom. (Madrid: Alianza, 1980-1984).

52 Edward Hallett Carr, La Revolución Bolchevique, 1917-1923 (Madrid: Alianza, 1977), 187. 
algo accesible al gran público, a los menos doctos o a los estudiantes. Aquí se situarían sus títulos La revolución rusa. De Lenin a Stalin, 1917-192953 O Estudios sobre la revolución. ${ }^{54} \mathrm{El}$ propio Carr lo justifica así:

Se me ocurrió que podría tener sentido destilar esta investigación en un libro corto de tipo muy diferente, sin refinamientos académicos tales como notas al pie o referencias a las fuentes, pensado para el lector común y para el estudiante que busca una primera introducción al tema. El resultado es esta breve historia. 55

Nos encontramos, pues, ante un intento serio de divulgación de la historia sin perder un ápice de cientificidad en el trabajo realizado. Por estas razones la obra de Carr es hoy en día una de las paradas obligatorias para el estudio de la Revolución rusa.

El balance general de la historiografía clásica fue el de un enorme peso de la carga negativa de la revolución y de los componentes de una historiografía conservadora, si bien la vitalidad que en los años de la Guerra Fría mostró el marxismo académico ofreció una serie de obras de primer nivel que se convirtieron en clásicos para el estudio de la revolución.

\section{Las novísimas investigaciones}

La caída del Muro de Berlín en 1989, el desplome de los países de la órbita comunista a través de procesos como la Revolución de Terciopelo, y la caída definitiva de la URSS en 1991, marcaron una crisis en la historiografía general sobre la Revolución rusa, sobre la propia disciplina histórica y, en especial, sobre la historiografía marxista, que había marcado parte de la influencia investigadora. No solo fue una crisis o el final de conceptos más ortodoxos, sino que las posiciones más analíticas como las de Hobsbawn o Thompson se vieron en crisis frente a posiciones teleológicas del "fin de la historia" con la victoria del capitalismo. Sin embargo, la visión de

53 Edward Hallett Carr, La Revolución rusa de Lenin a Stalin, 1917-1929 (Madrid: Alianza, 1985).

54 Ibídem.

55 Carr, La Revolución rusa de Lenin a Stalin, 7. 
Francis Fukuyama no se correspondió con la realidad, aunque la caída del bloque soviético significó varias cosas para los estudios de la Revolución rusa. En primer lugar, el acceso a los archivos soviéticos, hasta entonces herméticos al otro lado del muro, sirvió para ver con más perspectiva y con documentos de primera mano un proceso que cambió el siglo xx. En segundo lugar, se reforzó una posición historiográfica conservadora y crítica con el propio concepto de revolución y socialismo, que se ha dejado sentir de forma patente en el centenario de la revolución celebrado en 2017. A nivel de los estudios en España, el periodo que media entre la caída de la URSS y la actualidad sí ha servido para que algunos historiadores españoles se preocupasen por el desarrollo del proceso soviético y se convirtiese en una vía de investigación en nuestro país, aunque francamente minoritaria y con resultados desiguales.

Comenzando por las historias generales de la Rusia soviética, cabría destacar en este punto la obra de Moshe Lewin El siglo soviético. ¿Qué sucedió realmente en la Unión Soviética?, ${ }^{56}$ en la que repasa aspectos relevantes de la historia de la URSS, que engarza, en muchas ocasiones, con el propio proceso revolucionario de 1917. Se trata de un estudio valioso porque analiza las estructuras de funcionamiento del Estado y del partido sin ser un libro lineal, pues está estructurado en distintos bloques que se centran en los aspectos fundamentales de distintas épocas. Para el proceso revolucionario cabe destacar la tercera parte, «El tiempo y los mundos de Lenin», en la que se centra en la figura del fundador de la URSS y analiza las fuerzas revolucionarias o contestatarias de 1917, en un "combate" entre Miliukov y Lenin. El capítulo entra pues de lleno en la Revolución de 1917, destacando aspectos fundamentales de los debates que se dieron entre bolcheviques, constituyentes, Kerenski, Chernov, etc. El autor pone en relación la Revolución rusa de 1917 con la crisis de Europa en el periodo de la Primera Guerra Mundial (1914-1918), lo que significa contextualizar la revolución en un proceso internacional.

Lewin lleva cuestiones al campo del propio debate, donde se nota una inhibición de los encorsetamientos que se habían dado en el periodo de 
entreguerras y de Guerra Fría. A las preguntas «¿Qué es el bolchevismo?» $\mathrm{y}$ «¿Qué es el leninismo?», Lewin responde lo siguiente:

El bolchevismo era un partido, pero también era un ethos. Las discusiones podían versar sobre cualquier cuestión y no se detenían en la superficie. Aquí tenemos algunos ejemplos de los temas que se trataban en los órganos del Partido y en público. Gracias a la publicación de las actas del Comité Central desde agosto de 1917 hasta febrero de 1918, tenemos constancia de las discusiones acerca de la idoneidad de hacerse con el poder en 1917 y de si había que buscar aliados o no. 57

Igualmente, Lewin hace una buena diferenciación entre el periodo leninista (dictadura del partido) y el estalinismo (dictadura de un solo hombre): «La dictadura estaba en manos del Partido, no en las de Lenin. Cuando cayó en manos de un individuo, la cuota del poder del Partido no tardaría en esfumarse»..$^{8}$ Para Lewin — que coincide en parte con la visión que ya había dado Broué-, el Partido acabó disolviéndose y el XII Congreso marcó el fin del periodo revolucionario; el año 1924 supondría para él el fin del "bolchevismo", coincidiendo con la muerte de Lenin. En un proceso de análisis más profundo, lo que viene a concluir Lewin es que Rusia, tal como habían reconocido algunos líderes de la revolución, no estaba preparada para el socialismo, y lo que sucedió fue una reinvención del partido que, según el historiador, unía una forma de proceder nueva con la retórica del pasado. ${ }^{59}$ La obra de Lewin es, pues, una muy interesante historia social del periodo soviético, con más énfasis desde el periodo estalinista, y que introduce cuestiones de interés como la importancia y el alcance del bolchevismo, que el autor une irremediablemente a Lenin. Con todo, su estudio no deja de tener aspectos polémicos.

Entre las historias generales de la Revolución rusa escritas por historiadores españoles destacan La Revolución rusa, ${ }^{60}$ de Francisco Díez del

6o Francisco Díez del Corral, La Revolución rusa (Madrid: Anaya, 1998). 
Corral, y La Revolución rusa. La fábrica de una nueva sociedad, ${ }^{61}$ de María Teresa Largo Alonso, más reciente. De la primera es remarcable el esfuerzo de síntesis y esquematización del proceso revolucionario, si bien las aportaciones al campo de la investigación son escasas o nulas. Al haber conocido varias ediciones, hay que resaltar que el cometido de esta obra no es otro que el de la introducción al proceso revolucionario. Su valor radica en que es un material perfecto para preparar el tema de la Revolución rusa para alumnos de ESO y Bachillerato o para quin quiera introducirse de forma un poco más profunda en el estudio de la revolución. El libro de Largo Alonso tiene también la virtud de ser didáctico y divulgativo, a pesar de varios errores de contenido y de fondo - en ciertos nombres o en el origen de procesos como la fundación del soviet o los debates de los grupos políticos - y de la fuerte carga negativa que se le da a la revolución fruto de las interpretaciones de algunos historiadores conservadores, como se verá más adelante. Destacan aspectos que no se dan en otras obras de la Revolución rusa, como el papel protagonista de las mujeres en el proceso revolucionario, la importancia del cine para la trasmisión de la Revolución rusa o un interesante capítulo en que se introducen algunas cuestiones historiográficas que dan pie al inicio de un debate. ${ }^{62} \mathrm{~A}$ pesar de los errores o del desdibujo que sufren algunos personajes y procesos, hay aspectos de enorme valor en la obra.

La historiografía que ha tenido mayor producción bibliográfica en este tiempo ha sido la conservadora. La caída de la URSS y la disolución del bloque soviético posibilitaron que las visiones negativas de la Revolución rusa se viesen reforzadas y que se presentara el proyecto surgido de las jornadas de 1917 como un fracaso absoluto. Muchas de estas obras no están escritas por historiadores, sino por ensayistas o periodistas que no solo encontraron un hueco en los medios académicos, sino también en el campo publicitario. Se trata de obras traducidas a muchos idiomas y que son dispares en cuanto a resultados.

61 María Teresa Largo Alonso, La Revolución rusa. La fábrica de una nueva sociedad (Madrid: Los Libros de la Catarata, 2017).

62 Largo Alonso, La revolución rusa, 120-130 (para las mujeres), 160-170 (para el cine), 171-184 (para la historiografía). 
Uno de estos historiadores, de carácter liberal, es Robert Service, que ha trabajado la historia de Rusia desde dos perspectivas: el desarrollo histórico y la biografía. Gracias al acceso que tuvo desde 1991 a los archivos soviéticos, Service ha escrito, hasta la fecha, la biografía de Lenin, ${ }^{63}{ }^{3} \operatorname{Salin}^{64}$ y Trotsky. ${ }^{65}$ Todas las biografías, con diversos matices, cumplen unas cuestiones básicas. Están basadas en las fuentes primarias que el autor trabajó, pero buscan, sobre todo, los componentes autoritarios o totalitarios de los personajes para justificar el fracaso de la revolución y situar en el origen de la misma los componentes de la dictadura en la que desembocó el proceso. Todo ello se presenta con una carga ideológica producto de la ideología del autor, que viene a concluir en la inviabilidad de un proyecto socialista. Estas cuestiones se ven reforzadas en obras como Historia de Rusia en el siglo $x x .{ }^{66}$ Para ello el autor se documentó en los archivos federales de Moscú y en los archivos del partido en Smolensk, y en fuentes documentales y memorias de protagonistas. Dicha obra proyecta una enorme carga negativa sobre el comunismo y centra el tema principal en el fracaso del proyecto soviético. Esta tónica general se observa en obras del mismo autor como Rusia. Experimento con un pueblo ${ }^{67}$ o The Russian Revolution, 1900-1927, ${ }^{68}$ en cuya conclusión presenta el proceso revolucionario y sus resultados como un fracaso total de consecuencias tambien fatales para Rusia y para el mundo entero.

La obra de Orlando Figes presenta una perspectiva académica y una orientación conservadora similares. Partiendo de la idea de lo que significó el zarismo para la sociedad rusa, Figes se adentra en los orígenes del movimiento revolucionario ruso desde el siglo XIX, así como en las cuestiones propiamente rusas de la transformación política del país. Sin embargo, no deja de ser una aproximación excesivamente crítica de los revolucionarios. Maneja muchos datos y muestra que controla a la per-

63 Robert Service, Lenin. Una biografia (Madrid: Siglo xxI, 2004).

64 Robert Service, Stalin. Una biografia (Madrid: Siglo XxI, 2006).

65 Robert Service, Trotsky. Una biografia (Barcelona: Ediciones B, 2010).

66 Robert Service, Historia de Rusia en el siglo XX (Barcelona: Crítica, 200o). Existe una edición actualizada de 2016.

67 Robert Service, Rusia. Experimento con un pueblo (Madrid: Siglo xxi, 2005).

68 Robert Service, The Russian Revolution, 1900-1927 (Basingstoke: Palgrave Macmillan, 1999). 
fección algunas cuestiones, pero en ocasiones mezcla otras para reforzar unas conclusiones a claras luces predeterminadas. A pesar de ello, por su voluminosa obra pasean personajes que en muchas otras ni se citan: Axelrod, Lavrov, Chaikovski, grupos políticos como Zemliá y Volia, etc. La semblanza que ofrece de Lenin es sintomática:

En contra del mito soviético, que presentaba a Lenin como un teórico plenamente convencido del marxismo en sus primeros años, el dirigente de la revolución bolchevique accedió a la política bastante tarde. A los dieciséis años era todavía religioso y no mostraba ningún interés en absoluto por la política. Los clásicos y la literatura eran sus principales estudios en el instituto Simbirsk. Allí, por una de las curiosas ironías históricas, el director de Lenin era Fedor Kerensky, el padre de su archirrival en 1917. [...] No existía absolutamente nada que sugiriera que Lenin se iba a convertir en un revolucionario; por el contrario, según todas las indicaciones, seguiría los pasos de su padre y disfrutaría de una distinguida carrera en la burocracia zarista. ${ }^{69}$

No se olvida Figes de otros protagonistas de la revolución, y aborda a Majnó, a Antonov, a Kronstadt, etc., aunque de una forma deficiente. Para Kronstadt apenas cita a los protagonistas de la revuelta contra el poder bolchevique, si bien sí menciona en este momento a los testimonios de Alexander Berkman. Para Majnó la cuestión va mucho más allá y habla de una guerrilla "roja". Aunque ubica bien el majnovismo, que denomina en un momento dado el «Pancho Villa de la Revolución rusa». ${ }^{70}$ Y no deja de considerar a Majnó un revoltoso, sin considerar su movimiento como algo más: como un modelo distinto de revolución dentro del caleidoscopio de revoluciones que se generó con el proceso revolucionario de 1917. También incurre en el error de equiparar las acciones de Grigoriev con las de Majnó, acusando a ambos de pogromos antijudíos, cuando está demostrado que Majnó no promovió ninguno. La imagen que Figes transmite de Majnó no es benevolente. ${ }^{71}$ Por otro lado, es interesante cómo Fi-

69 Orlando Figes, La Revolución rusa (1890-1924). La tragedia de un pueblo (Barcelona: Edhasa, 2000), 181-182.

70 Figes, La Revolución rusa, 722.

71 Ibídem. 
ges centra la atención en varios personajes como Lenin, Trotsky, Gorki, Os'kin, Lvov, Kerensky, etc., que al final son hilos conductores y motivos recurrentes en el libro. La última parte de la obra es la anticipación a las luchas por el poder que se produjeron en el interior del partido tras la muerte de Lenin. Estamos ante una historia de la Revolución rusa de carácter lineal que, a pesar de la enorme carga negativa que Figes concede a la revolución y la visión excesivamente negativa de algunos de sus protagonistas, posee un importante aparato crítico y una amplia bibliografía, lo que le concede un valor significativo.

Sin alcanzar la voluminosidad de las obras de Service o Figes, una de las novedades editoriales que nos ofreció el centenario de la Revolución rusa desde la perspectiva conservadora fue la obra de Mira Milosevich Breve historia de la Revolución rusa..$^{72}$ Milosevich, licenciada en Sociología y Ciencias Políticas, doctorada en Estudios Europeos e investigadora del Real Instituto Elcano, ha realizado la más elocuente obra de carácter conservador que se ha publicado en castellano. El libro, a pesar de recalcar en el título su brevedad, pretende ser una historia total de la URSS, trazando un hilo desde los movimientos revolucionarios del siglo xIx hasta Putin. Una de las primeras cuestiones que Milosevich establece es el paralelismo entre el Estado zarista y el Estado comunista tras octubre de 1917. Esta hipótesis no es nueva en el campo de la historiografía conservadora, pero Milosevich la personaliza en la figura de Lenin:

El Estado bolchevique establecido por Lenin, el 'Pugachov de la universidad', fue desmesuradamente más absoluto y tiránico que el zarista, aunque aprovechó en gran medida la estructura del Estado patrimonial, con su administración centralizada y ausencia de libertades individuales y propiedad privada de la mayoría de los súbditos del zar. ${ }^{73}$

La autora comparte la idea de que el siglo XIX es importante para entender las transformaciones revolucionarias del siglo $\mathrm{xx}$ ruso, pero niega la trascendencia que pudieran tener los movimientos políticos revolucio-

72 Mira Milosevich, Breve historia de la Revolución rusa (Barcelona: Galaxia Gutemberg, 2017).

73 Ibídem, 33 . 
narios para ello. Aunque traza una línea de los principales movimientos socialistas del siglo xix y de algunos movimientos revolucionarios - con algún error, como considerar a Proudhon un socialista utópico-, la conclusión de la autora es que esos movimientos no provocaron ningún cambio político y sí generaron una dura represión por parte del zarismo. Milosevich sitúa el populismo, el movimiento más prototípico del momento, en la base del desarrollo del bolchevismo y de las ideas de Lenin, y reduce las actividades de los populistas al asesinato y al terrorismo.74

Sin embargo, parece que la autora no toma en cuenta otros estudios que afirman que, si bien el populismo, que tuvo su raíz en Herzen y cristalizó en movimientos políticos como Narodnaïa Volia, influyó en el bolchevismo — como en la práctica totalidad de los revolucionarios rusosno fueron los bolcheviques los verdaderos deudores de dicho movimiento. El Partido Socialista Revolucionario es el continuador natural del concepto y la autora le concede pocos párrafos en la obra en comparación a los socialdemócratas. Además, remarca la ola de atentados que se produjeron en Rusia en el inicio del siglo xx y los vincula al anarquismo, a pesar de que las nuevas investigaciones sobre el anarquismo - que se reseñarán más adelante- no ponen a los libertarios como los protagonistas de ese proceso. Por otro lado, Milosevich destaca la importancia de la mujer en Rusia, pero rompe con los historiadores que muestran los avances de la mujer durante y tras el proceso revolucionario de 1917, considerando que esos avances ya se dieron con el zarismo, donde la mujer alcanzó un mayor estatus de participación política, social y de acceso a la Universidad.

Teniendo en cuenta lo ambicioso del texto al querer abarcar una enorme cantidad de años en pocas páginas, Milosevich analiza de forma sucinta la visión de los bolcheviques respecto a la Primera Guerra Mundial, la Revolución de Febrero de 1917 y la cuestión de la dualidad de poderes en el periodo que media entre febrero y octubre. Igualmente, hay dos cuestiones que siguen siendo objeto del debate historiográfico y en las que la autora tiene una posición muy clara. En primer lugar, que Lenin fue un agente del gobierno alemán o, a lo sumo, que estuvo pagado por ellos para poder originar un movimiento revolucionario que provocase la salida de

74 Ibídem, 48. 
Rusia de la guerra. En segundo lugar, que lo que sucedió en octubre de 1917 no fue una revolución, sino un golpe de estado de los bolcheviques para hacerse con el poder, si bien tuvieron una base social que intentaban canalizar desde febrero de 1917.

En cuanto a la represión y el terror, con la creación de la Cheká en diciembre de 1917, Milosevich los sitúa en julio de 1918 con el asesinato de la familia Romanov, pero obvia que dicha represión había comenzado antes en las disputas que mantenía el campo revolucionario en el propio concepto de la revolución. Para este aspecto la autora habla exclusivamente de los debates que los revolucionarios tuvieron alrededor de la Asamblea Constituyente y su cierre por parte del gobierno de los soviets. Sin embargo, Milosevich no concede importancia a los debates de la izquierda en torno a la cuestión de la tierra, el control obrero y la paz, pues fue BrestLitovsk el canto del cisne de la coalición no firmada entre bolcheviques, socialistas revolucionarios de izquierda — que apenas tienen presencia en el libro - y anarquistas. Esta cuestión no fue un debate exclusivo en el interior del Partido Bolchevique, ya en el poder, sino de toda la izquierda revolucionaria en su conjunto.

Al igual que sucede con otros temas del libro, Milosevich analiza de forma superficial cuestiones de gran interés, como la Guerra Civil rusa o la rebelión de los marinos de Kronstadt en 1921, y concluye finalmente, cuando se refiere a los debates que se dan en el X Congreso del Partido Comunista alrededor del desarrollo de la NEP, que el comunismo de guerra fue la base del estalinismo, y que la maquinaria represiva de la Cheká sería fundamental para la victoria bolchevique. ${ }^{75}$ La conclusión de Milosevich es que el tema fundamental de la política bolchevique fue el totalitarismo y la violencia. Que incluso el repliegue de Lenin y Trotsky respecto a la NEP no deja de ser la base para la futura política de Stalin, al considerar el fracaso de la propia NEP y derogarla en 1928. Aquí entra en colisión con los estudios de Stephen F. Cohen, que considera que la NEP era la verdadera naturaleza del leninismo y que Stalin revierte lo hecho por Lenin.

Milosevich divide en cuatro fases los debates alrededor de la sucesión de Lenin: a) triunvirato Stalin-Zinóviev-Kámenev (hasta la muerte de

75 Ibídem, 116. 
Lenin en enero de 1924); $b$ ) Stalin y el socialismo en un solo país y Trotsky y la revolución permanente; c) alianza Trotsky-Zinóviev-Kámenev, y d) imposición de Stalin y expulsión de Trotsky. No deja de ser interesante el eje que establece la autora del concepto de "revolución permanente" desde el siglo XIX, aunque incluya en un mismo bloque tendencias del socialismo que están muy separadas entre sí.

Siguiendo un concepto conservador muy extendido entre muchas obras, Milosevich no encuentra apenas diferencias entre el comunismo y el nazismo-fascismo. Aunque establece algunas diferencias ideológicas, todas parten del mismo concepto totalitario de la sociedad. ${ }^{76}$ El libro continúa con un repaso a toda la época estalinista, Jruschov, Brezhnev, el interregno Andropov-Chernenko y la llegada de Gorbachov. La conclusión final, en la incursión que hace en la Rusia de Putin, es que, a pesar de las diferencias ideológicas, hay enormes semejanzas entre la URSS y Putin. En definitiva, el libro de Milosevich no deja de ser una obra propia del conservadurismo historiográfico: la autora, a partir de ideas preconcebidas, intenta rellenar los huecos para justificar su teoría. Hay saltos y silencios importantes en el libro que, debido probablemente a su brevedad, hace que queden cojas muchas cuestiones de interés. Para la autora la URSS se convirtió en un sistema de recompensas en el que la ideología solo era una fachada, y el terror y el totalitarismo los pilares fundamentales de la sociedad. ${ }^{77}$

Lo mismo que la Revolución francesa tuvo divulgadores que desde el conservadurismo dieron una visión más opinativa que científica, como fue el caso de François Furet, la Revolución rusa también los tiene. Quizá el más famoso de todos sería el recientemente fallecido Richard Pipes y su voluminosa obra La Revolución rusa..$^{8} \mathrm{Su}$ obra, basada en conclusiones personales, es un libro lineal completo y con una enorme carga anticomunista, que ha servido como base de muchas de las historias de carácter conservador sobre la Revolución rusa. De hecho, Pipes es citado en ocasiones por autores anteriores como Figes o Milosevich como referencia

76 Ibídem, 141-142.

77 Ibídem, 275-276.

78 Richard Pipes, La revolución rusa (Barcelona: Círculo de Lectores, 2016). 
a sus propios estudios. Pipes, que podría ser considerado un revisionista en cuanto a su modo de entender el desarrollo revolucionario ruso, tiene la virtud de utilizar la divulgación como canal de trasmisión de sus ideas respecto al proceso, llegando a mucho más público que por los canales académicos. En una entrevista que se le realizó unos meses antes de su muerte, y en el marco del centenario de 1917, definía así la Revolución rusa: «La Revolución rusa fue uno de los sucesos más trágicos del siglo xx. No hubo absolutamente nada positivo ni grandioso en aquel acontecimiento.»79

En una línea también conservadora se encuentra el trabajo publicado por Catherine Merridale El tren de Lenin. Orígenes de la Revolución ru$s a .^{80} \mathrm{El}$ argumento de Merridale es sencillo: Lenin actuó con el beneplácito de Alemania para poder introducirse en Rusia y así provocar la caída del gobierno provisional de Kerensky y sacar al país de la Primera Guerra Mundial. Con esta conclusión, la autora concede un segundo lugar a los movimientos del interior o a la actividad de los movimientos revolucionarios. En realidad estamos ante una historia de espías, con personajes como Parvus o Këslulla, y de políticas secretas, que da carta de naturaleza a fuentes no demostradas como las memorias de Kerensky (que acusa directamente a Lenin de ser un agente alemán), las tesis de Ermolenko (que habla de un contrato) y las de Nikitin o las de George Kenan ya citadas. Ninguna de ellas demuestra en ningún caso que Lenin estuviese a sueldo de los alemanes o que hubiese un vaso comunicante entre los agentes del Kaiser y los bolcheviques. Sin embargo, es un tema recurrente en la historiografía de la Revolución rusa, sobre todo en la conservadora.

Una cuestión que no ha suscitado mucho interés en el centenario de la revolución es la vida de los zares. Aunque no ha sido mucha la bibliografía al respecto, el historiador Simón Sebag Montefiore nos ha dejado una voluminosa obra sobre los Romanov que abarca los 300 años de existencia de la casa real. El autor desarrolla un esquema al estilo de una obra de teatro. Al inicio de cada uno de los capítulos que componen el libro, el autor hace una relación de los personajes más importantes del periodo, lo que ayuda a la comprensión de cada parte. La última es la más

79 «Entrevista de Eduardo Lago a Richard Pipes», El País. Babelia, 27 ene. 2017.

8o Catherine Merridale, El tren de Lenin. Orígenes de la Revolución rusa (Barcelona: Crítica, 2016). 
interesante en relación con la Revolución de 1917 porque analiza dicho proceso. La obra tiene una fuerte base documental y un gran número de lecturas, así como cuadros genealógicos explicativos y mapas de enorme importancia. Pero en muchas ocasiones peca de idealización de algunos zares concretos como Pedro el Grande o Catalina II. En el caso de la Revolución de 1917, el autor denota su enorme carga crítica con la revolución y su posición abiertamente anticomunista, lo que hace que muchas cuestiones relacionadas con el movimiento revolucionario formen parte de los lugares comunes de la historia. Igualmente insiste, ya en el epílogo, en la asimilación de los zares rojos, denominando así a los mandatarios de la URSS, algo muy común en la crítica conservadora de la Revolución rusa de $1917 .^{81}$

La participación de los extranjeros en la Revolución rusa ya se analizó en la primera parte de este estudio a través de las memorias de sus protagonistas. Pero el centenario de la revolución fue el motivo para que Helen Rappaport abordase de forma más detenida la implicación de los extranjeros en el proceso revolucionario con el libro Atrapados en la Revolución rusa.$^{82}$ Rappaport no es la primera vez que se adentra en la historia de Rusia, pues de su pluma han salido una biografía de Stalin - Stalin. One Biography - y dos trabajos sobre la familia Romanov - Las hermanas Romanov y The Last Days of Romanovs - . Desde una perspectiva conservadora, Rappaport recupera a muchos de los extranjeros que participaron en la Revolución rusa en un libro a medio camino entre la obra literaria y el ensayo histórico. Distingue tres tipos de extranjeros en la Rusia revolucionaria: los extranjeros contrarios a la revolución y cercanos a la corte del zar, en su mayoría aristócratas; los que vieron como positiva la Revolución de Febrero y los cambios en una línea liberal, pero que se mostraron opositores a la Revolución de Octubre, y los que apoyaron la transformación revolucionaria de octubre, como los ya citados John Reed, Louis Bryant o Albert Rhys William.

El trabajo de Rappaport es novedoso no solo por analizar de forma pormenorizada las vivencias de los extranjeros, sino por el espacio que de-

81 Simón Sebag Montefiore, Los Romanov, 1613-1918 (Crítica: Barcelona, 2016), 835-838.

82 Helen Rappaport, Atrapados en la Revolución rusa (Madrid: Palabras, 2017). 
dica a otros personajes: las mujeres extranjeras que visitaron Rusia, por ejemplo Emmeline Pankhurst, Jessie Kesnay o Ritta Child Door. También, como dato más curioso, da voz a un personaje negro en la Revolución rusa: Phil Jordan, mayordomo del embajador norteamericano David R. Francis. Asimismo, aparecen políticos como Sir George Buchanan, embajador británico en Rusia, y su My Mission to Russia and Other Diplomatic Memoirs, o Maurice Paléologue, diplomático francés, con obras como La Russie de tsar pendant la Grande Guerre o Les Précurseurs de Lénine.

Pero no todas las obras que se han desarrollado sobre la Revolución rusa tras la desaparición de la URSS han sido de cariz conservador. Aunque todas han trabajado el fenómeno de la violencia, es quizá la obra de Arno J. Mayer Las furias. Violencia y terror en las revoluciones francesa y rusa la que mejor lo ha hecho. La monumental obra de Mayer hace una comparativa de las violencias en ambas revoluciones. Además, con buen criterio, el autor establece que ambos procesos tuvieron defensores y detractores desde su inicio y que hay quien considera que los comunistas de la época eran los herederos jacobinos de 1789. Resulta interesante la comparativa que establece entre la violencia de la Vendée y los movimientos de Majnó y Antonov, con todas las diferencias que existen entre ellos. La violencia también ha sido trabajada, con menos brillantez, pero con un trabajo de gran valor, por James Harris en El gran miedo. Una nueva interpretación del terror en la Revolución rusa, ${ }^{83}$ donde analiza la política del terror de los bolcheviques. Estos libros se convierten en paradas obligatorias para entender el concepto del terror y su aplicación en un proceso revolucionario.

Ha pasado casi desapercibida la obra del ya citado Stephen F. Cohen, como autor a caballo entre la historiografía durante la Guerra Fría y la sociedad postcomunista. Cohen, historiador emérito de Princeton, habló durante la Guerra Fría de la necesidad de relajar la confrontación entre bloques para que la URSS pudiese acometer las reformas necesarias. Algo que en el ambiente anticomunista de la época se tomaba casi como una invitación a la defensa del comunismo. La obra de Cohen está poblada

83 James Harris, El gran miedo. Una nueva interpretación del terror en la Revolución rusa (Barcelona: Crítica, 2017). 
de grandes libros y estudios sobre el periodo estalinista y el fracaso que supuso el mismo para la propia Revolución rusa. Pero en los momentos finales de la URSS y coincidiendo con su caída, Cohen rescató a una de las figuras más interesantes de la revolución: Nikolai Bujarin. En Bujarin y la revolución bolchevique. Biografía política, $1888-1938{ }^{84}$ viene a confirmar que el sucesor natural e ideológico de Lenin era Bujarin y que el bujarinismo era la continuación del leninismo cortada de súbito por el ascenso de Stalin. Al final, la oposición de Bujarin a la colectivización forzosa y a la industrialización rápida, así como la disidencia que mantenía en el interior del Partido Comunista, le llevó a su ejecución por la policía política estalinista. Aprovechando que Bujarin fue rehabilitado en 1988 por el gobierno de Gorbachov y que Cohen estaba en una estancia en la capital rusa, desarrolló esta interesante investigación a caballo entre una típica biografía y la recuperación de un periodo poco claro en el proceso revolucionario.

Uno de los libros que con motivo del centenario más ha sorprendido ha sido el de China Miéville Octubre. La historia de la Revolución rusa. ${ }^{85}$ Miéville no es un historiador sino un novelista, con una escritura más amena. No estamos ante una obra académica, sino ante un ensayo que tiene la virtud de abordar cuestiones apenas trabajadas en otras obras. Sorprenden los conocimientos de Miéville sobre personajes y procesos que han pasado desapercibidos a lo largo de la historia, como la reconstrucción del soviet de Petrogrado en 1917, la riqueza de la diversidad de tendencias políticas durante la revolución o la participación de los musulmanes, que lejos de las visiones más cerradas del Islam, se unen a la revolución con la reivindicación de todos los derechos para la mujer: «El centro de gravedad de las discusiones era claramente jadidista, o más a la izquierda. Un síntoma de tiempo de cambio». ${ }^{86} \mathrm{Hila}$ fino el autor incluso en acontecimientos que menos han trascendido, como la ocupación de la Dacha Durnovo en Petrogrado por los anarquistas durante la primavera de 1917 y el conflicto que se generó al respecto entre el Soviet de Petrogrado, el de Kronstadt y

84 Stephen F. Cohen, Bujarin y la revolución bolchevique. Biografia política, 1888-1938 (Madrid: Siglo XXI, 2017).

85 China Miéville, Octubre. La historia de la Revolución rusa (Madrid: Akal, 2017).

86 Ibídem, 129.

DICTATORSHIPS \& DEMOCRACIES 6 (2018) · EISSN: 2564-8829 · PUNCTUM, UNIVERSITAT OBERTA DE CATALUNYA \& FUNDACIÓ CARLES PI I SUNYER 
el Gobierno Provisional. Igualmente, el autor desautoriza la cuestión de Lenin y su contacto con el Kaiser trabajando sobre las fuentes primarias de la época ${ }^{87}$ desdiciendo a la historiografía conservadora.

Pero no es Miéville un hagiógrafo de la revolución. Es muy crítico con el resultado de octubre de 1917 y el terror que desató la Cheká. Su análisis del terror rojo no deja de ser también bastante acertado, pues lo contextualiza para su comprensión:

El acosado nuevo régimen desata su propio Terror Rojo. Y no hay duda de que su alcance y profundidad llegan a estar fuera de control; algunos agentes de la Cheká, la policía política, seducidos por el poder personal, el sadismo o la degradación del momento, son matones y asesinos sin convicción política que los frene en su nueva autoridad. No escasean los testimonios respecto a sus terribles actos. ${ }^{88}$

Aunque el autor no ha trabajado con los documentos de archivos de la época, su bagaje de lecturas es importante y la obra es muy interesante, en la medida que aborda cuestiones que otras, más académicas, no tratan.

La historiografía puramente marxista no ha salido bien parada en el centenario y apenas han aparecido libros que hayan aportado algo sustancial a lo dicho por otros autores hace ya décadas. Quizá habría que destacar $L a$ Revolución rusa. Una historia del pueblo, de Neil Faulkner, ${ }^{89}$ el cual defensa la revolución desde una perspectiva puramente marxista y antiestalinista. Los objetivos se marcan claramente en la introducción del libro: demostrar que Lenin era un demócrata — no un "centralista democrático"- y el Partido Bolchevique, un movimiento democrático de masas - no una secta seudorrevolucionaria-; que la revolución respondió a un movimiento popular de masas basado en los principios de la democracia participativa - no un golpe de mano orquestado para instaurar una dictadura-, y que el estalinismo fue un movimiento contrarrevolucionario que acabó con el Partido Bolchevique y con la democracia soviética..$^{\circ 0}$ Aunque acier-

87 Ibídem, 202-203.

88 Ibídem, 327.

89 Neil Faulkner, La Revolución rusa. Una historia del pueblo (Madrid: Capitán Swing, 2017).

90 Ibídem, 16. 
ta el autor al considerar que muchos de los estudios elaborados sobre la Revolución rusa en el periodo de la Guerra Fría estaban mediatizados por el entorno y por un fuerte anticomunismo, la obra de Faulkner aglutina un componente puramente marxista que hace que en muchas ocasiones se pierda la complejidad del proceso revolucionario ruso reduciéndolo exclusivamente al bolchevismo y reivindicando la figura de Trotsky. Los movimientos políticos socialistas no bolcheviques apenas tienen cabida en la obra. Pero lo cierto es que en el debate sobre si octubre de 1917 fue un golpe de estado o no lo fue, Faulkner es categórico en su afirmación al negar cualquier posibilidad de golpe por la pérdida de fuerzas sociales y abandono que tuvo el Gobierno Provisional. ${ }^{91}$

El otro eje destacable de la obra de Faulkner es poner el límite de la revolución. Si para la historiografía conservadora las diferencias entre Lenin y Stalin son mínimas, y para la historiografía que rescata a otros movimientos políticos, como el anarquismo, el final de la revolución se produce en 1921-1922 con la derrota de Majnó, de Kronstadt y de Antonov en Tambov, la historiografía marxista heterodoxa sitúa el final de la revolución con la muerte de Lenin y los debates surgidos a posteriori que dieron la victoria total a Stalin. Para Faulkner la victoria estalinista supone el final de la revolución y la liquidación del Partido Bolchevique o Comunista. A pesar de ser un libro interesante, la obra de Faulkner peca de un maniqueísmo del que también es partícipe la historiografía conservadora.

A nivel internacional cabría destacar las apreciaciones que el pensador neomarxista Samir Amin realizó en la obra La Revolución de Octubre cien años después. ${ }^{92}$ El texto no aporta nada al campo historiográfico, pero recoge las reflexiones de un pensador marxista crítico con los resultados del proceso revolucionario ruso.

Si algo ha sorprendido en el año del centenario han sido las aportaciones de la historiografía española, no solo por el impacto que la Revolución rusa pudo tener en España - cuestión que ya abordaron tiempo atrás historiadores como Juan Avilés Farré-,${ }^{93}$ sino por las contribuciones que

91 Ibídem, 180.

92 Samir Amin, La Revolución de Octubre cien años después (Barcelona: El Viejo Topo, 2017).

93 Juan Avilés Farré, La fe que vino de Rusia. La revolución bolchevique y los españoles (1917-1931) (Madrid: Biblioteca Nueva / UNED, 1999). 
nuestros historiadores han ofrecido al propio estudio de la revolución en Rusia. De entre estas obras, habría que destacar cuatro de carácter general y dos de carácter específico que han abordado otras aristas de la revolución. Antes de entrar en ellas, habría que destacar una obra que no es específicamente sobre la Revolución rusa, pero que le dedica un amplio capítulo. Nos referimos al libro del recientemente fallecido Josep Fontana El siglo de la revolución, donde se lee desde muy pronto la importancia que el proceso tuvo en la sociedad contemporánea:

La revolución rusa de 1917 siguió una trayectoria muy distinta y se convirtió en un nuevo modelo de praxis revolucionaria, que aportaba, como cambio fundamental, una nueva herramienta de lucha: el protagonismo de los consejos — los "soviets" en lengua rusa - de trabajadores, campesinos y soldados, que se presentaba como la base de una nueva forma de organización social en la que poder ir de abajo a arriba. ${ }^{94}$

Fontana realiza un serio análisis del significado y las consecuencias de la Revolución de 1917, analizando cuáles eran los propósitos de los revolucionarios, cuáles fueron sus resultados y la reacción que provocó a nivel internacional el vuelco de la situación en Rusia. Para Fontana el proceso ruso es prototípico de dicho país y difícilmente hubiese podido implementarse en otro lugar. Aun así, las derrotas revolucionarias en Alemania o Hungría marcaron el curso de una hipotética revolución mundial. Por otra parte, Fontana, a diferencia de otros historiadores marxistas, sí marca una continuidad revolucionaria durante el estalinismo, pero bajo otros parámetros que nada tenían que ver con los anteriores. ${ }^{95}$ Además, Fontana se muestra como un perfecto conocedor de los debates dados en el interior del comunismo ruso entre las distintas tendencias (Bujarin, Stalin, Zinoviev, Trotsky). Y aunque afirma que la deriva autoritaria y la ortodoxia fueron los peores enemigos del comunismo internacional, lo cierto fue que la Revolución de 1917 provocó una importante reacción anticomunista que duró todo el siglo xx y que, a pesar de todos los fraca-

94 Josep Fontana, El siglo de la revolución. Una historia del mundo desde 1914 (Barcelona: Crítica), 58. 95 Ibídem, 98. 
sos, la idea del comunismo seguía siendo en muchos entornos mundiales un sinónimo de alternativa y de transformación. ${ }^{96}$

De los libros específicos escritos por historiadores españoles, el más mediático ha sido el de Julián Casanova La venganza de los siervos. Rusia 1917. ${ }^{97}$ A partir de la frase del Príncipe Lvov, Casanova compone un libro sencillo e intenso, fácil de leer, que aporta una visión general al año 1917 y hace entender muchos componentes del proceso revolucionario, sin olvidar en ningún caso los antecedentes y, tampoco, los consecuentes, que analiza en un epílogo. Además aborda cuestiones que no se analizan en otras obras, como el protagonismo de las mujeres en el proceso revolucionario. Respaldado por un fuerte contenido bibliográfico, Casanova logra articular un trabajo que en menos de doscientas páginas sintetiza el año de la revolución. Entre las carencias del libro habría que citar que los antecedentes se tratan de forma muy sintética y que quizá se echan en falta posteriormente para analizar el año 1917. Igualmente, el libro centra mucho la atención en los bolcheviques y pierde la riqueza de la diversidad de tendencias en el proceso revolucionario. Sin embargo, Casanova es capaz de apreciar que lo que sucedió ese año no fue una revolución sino muchas, lo que hace que la obra sea novedosa y contribuya al avance historiográfico de la materia.

Otra gran aportación al centenario la ofreció el profesor e historiador José María Faraldo con su obra La Revolución rusa. Historia y memoria. $9^{8}$ Entre la interpretación, la reflexión y la investigación, Faraldo compone una obra conceptual donde algunas cuestiones son definidas en su justa medida. El gran valor del libro de Faraldo es su conocimiento exhaustivo de las fuentes rusas y de su idioma, lo que hace que las interpretaciones de algunos aspectos nodales del proceso revolucionario sean de parada obligatoria. El inconveniente de esta obra estriba en que para leerla hacen falta muchos conocimientos previos, de modo que no se trata de un trabajo para profanos. Eso no quita ni un ápice de importancia a una de las grandes contribuciones reflexivas sobre el proceso que cambió la historia

96 Ibídem, 636.

97 Julián Casanova, La venganza de los siervos. Rusia, 1917 (Barcelona: Crítica, 2017).

98 José María Faraldo, La Revolución rusa. Historia y memoria (Madrid: Alianza, 2017). 
de la humanidad, pues introduce dentro del campo historiográfico español debates sobre la Revolución rusa que hasta ahora eran inexistentes.

Como obra colectiva hay que destacar el libro, coordinado por los historiadores Fernando Hernández Sánchez y Juan Andrade, 1917. La Revolución rusa cien años después. ${ }^{99} \mathrm{El}$ libro recoge las aportaciones de veinticinco historiadores e investigadores nacionales y extranjeros, entre ellos algunos ya citados aquí como José María Faraldo o Josep Fontana. Los coordinadores han ensamblado una obra colectiva de enorme valor que es indicativa de la importancia que están tomando los estudios sobre la Revolución rusa y sus consecuencias en el panorama historiográfico de nuestro país. Además, es una obra que reúne desde la reflexión histórica hasta el trabajo de investigación, una muestra más de la importancia que adquiere la historia del tiempo presente.

Pero quizá la obra que más ha sorprendido por las novedades que introduce respecto al panorama general de la Revolución rusa es la de Francisco Veiga, Pablo Martín y Juan Sánchez Monroe: Entre dos octubres. Revoluciones y contrarrevoluciones en Rusia (1905-1917) y Guerra Civil en Eurasia. ${ }^{100}$ La importancia del libro radica en varios aspectos que habían sido poco trabajados. Al espacio temporal acotado entre las revoluciones de $1905 \mathrm{y}$ 1917 se une el ámbito espacial, pues el conflicto civil iniciado en Rusia en 1918 abarcó un ámbito mayor y tuvo implicaciones internacionales. Además aborda cuestiones exclusivamente militares en muchas ocasiones y no tanto políticas, lo que supone una novedad de investigación que no se había dado en este aspecto en nuestro país. Los autores marcan desde el principio la necesidad de alejar el estudio de la Revolución rusa de las concepciones políticas y hacen una crítica a historiadores como Orlando Figes, que, al calificar el proceso ruso como "la tragedia de un pueblo", predeterminan el estudio del acontecimiento. Por otra parte, los autores no desgajan la revolución de su época sino que la consideran un resultado de la Belle Époque que se extiende de 1868 a 1917 y que deriva en revoluciones en Japón (1868), México (1910) o China (1911), cada una con parámetros

99 Juan Andrade y Fernando Hernández Sánchez, coord., 1917. La Revolución rusa cien años después (Madrid: Akal, 2017).

100 Francisco Veiga, Pablo Martín y Juan Sánchez Monroe, Entre dos octubres. Revoluciones y contrarrevoluciones en Rusia (1905-1917) y Guerra Civil en Eurasia (Madrid: Alianza, 2017). 
distintos. No deja de ser una visión que recupera el debate del atlantismo que se dio en la Revolución francesa en autores como Godechot o Rudé.

Con 241 páginas de antecedentes a 1917, la obra ofrece una visión bastante certera de la situación de Rusia y de los revolucionarios en vísperas de dicha revolución. Analiza en esos antecedentes el siglo xIX, la represión del régimen zarista, el avance de grupos políticos como los socialdemócratas, socialistas revolucionarios, socialistas polacos y lituanos (no se cita a los anarquistas), el nacimiento del soviet, etc. Completa los antecedentes con los resultados de la Revolución de 1905 y la oleada conservadora que se impone en Rusia hasta el estallido de la Primera Guerra Mundial. Es quizá uno de los pocos trabajos que delimita muy bien los espacios ideológicos y de grupos políticos sin obviar la porosidad del propio momento histórico, además de introducir denominaciones certeras para analizar los procesos políticos. La Revolución de Febrero de 1917 es denominada por los autores como "nacional-republicana”. Y esos límites espaciales ideológicos se muestran a la perfección cuando analizan el renacimiento del soviet de Petrogrado en 1917, donde sitúan a mencheviques como Chjeidze o denominan, acertadamente, como trudovique a Kerensky. ${ }^{101}$

Son interesantes las conclusiones que extraen sobre el posible contacto de Lenin con los alemanes. Según ellos, el líder revolucionario ruso no tenía ningún interés en hacer el juego al Kaiser y sí llegar lo antes posible a Petrogrado a cualquier precio. En el juego de manipulación que se dio entre Lenin y Parvus para alcanzar sus respectivos objetivos, para los autores ganó el líder bolchevique. También se explica con enorme sencillez que la victoria fácil de los revolucionarios en octubre de 1917 se debió, sobre todo, a la debilidad del gobierno provisional de Kerensky, que no supo canalizar el descontento y fue perdiendo apoyo social, lo que aleja a los autores de la idea de un golpe de estado. ${ }^{102}$

Lo interesante de la obra se completa con los análisis que hacen los autores de la internacionalización de la revolución y el estallido de la Guerra Civil. Operaciones militares y bandos en liza, estos capítulos sirven para poner un orden necesario a las distintas tendencias que se dieron

101 Ibídem, 276-277.

102 Ibídem, 402.

DICTATORSHIPS \& DEMOCRACIES 6 (2018) · EISSN: 2564-8829 · PUNCTUM, UNIVERSITAT OBERTA DE CATALUNYA \& FUNDACIÓ CARLES PI I SUNYER 
cita en aquel conflicto civil: la organización del Ejército Rojo, la diversidad de los denominados blancos, movimientos de enorme importancia como el majnovismo en Ucrania, etc. Sin olvidar en ningún momento la maquinaria represiva que desarrollaron los bolcheviques en el poder y que laminaron su oposición a derecha e izquierda, los autores se centran sobre todo en los socialistas revolucionarios. Estamos pues ante un trabajo muy completo (aunque no utilice fuentes primarias), que en breves capítulos sintetiza a la perfección la Revolución rusa con variables que no abordan todas las obras. Además, la presencia de un militar entre sus autores da solvencia a esa parte de la historia que se quiere abordar. Es una gran aportación a la historia general en el año del centenario y destaca, en especial, la enorme cantidad de espacio que dedica a los antecedentes para poder entender bien lo ocurrido en 1917.

Para completar las aportaciones que se han dado en el panorama historiográfico español hay que hacer mención a unas obras que han abordado una cuestión más concreta de la Revolución rusa. A lo largo del texto se ha hecho referencia a aspectos generales de la Revolución rusa, así como a cuestiones concretas que se han abarcado en monografías o dentro de las historias generales. Existe una enorme cantidad de estudios generales o biográficos de los personajes principales de la revolución; sin embargo, la historiografía ha sido menos generosa con aquellos agentes que, aun participando en el proceso revolucionario y siendo protagonistas, no han pasado a la historia por diversas razones. La primera porque en el combate historiográfico que se entabló entre liberales y marxistas los estudios se centraron en los agentes triunfadores de aquel proceso: los bolcheviques. Sin embargo, el caleidoscopio de revoluciones del que hablaba Julián Casanova indica que la historia no la puede hacer solo un agente y que su porosidad ha hecho que por sus vetas se filtren otros protagonistas hasta desaparecer. Pocos saben, incluso en el ámbito académico, qué era un trudovique, qué era Yeditsvo o Novaya Zihn. No hay estudios pormenorizados a nuestro alcance sobre grupos políticos como los socialistas revolucionarios, que, en definitiva, eran los mayoritarios en Rusia. Sin embargo, la historiografía española ha tenido la peculiaridad de aportar dos obras que hablan de esos agentes protagonistas postergados por la historia. El historiador Julián Vadillo y el profesor de Ciencia Polí- 
tica Carlos Taibo publicaron en el año del centenario dos libros relativos a la historia del anarquismo en Rusia.

El libro de Julián Vadillo, Por el pan, la tierra y la libertad. El anarquismo en la Revolución rusa, ${ }^{103}$ es una historia lineal del anarquismo en Rusia desde sus orígenes en el siglo XIX hasta el exilio de los anarquistas tras la victoria comunista en la Guerra Civil rusa y su postergación en todo el escenario político. La obra, elaborada a partir de fuentes primarias y secundarias, quiere ser un acercamiento, pues como dice el autor en la introducción: «El libro que se presenta aquí tan solo es una modesta aportación que ha tratado de compilar en pocas páginas un proceso amplio en el tiempo» ${ }^{104}$ Además, en un intento de unir la investigación con la divulgación, el libro carece de notas a pie de página, que se suplen con un comentario de las fuentes documentales en las que se ha basado.

Por su parte, Carlos Taibo con Anarquismo y revolución en Rusia, 1917$1921^{105}$ realiza un acercamiento a la historia y actividad del anarquismo ruso en un espacio temporal más acotado que Vadillo y se centra más en las cuestiones de cariz ideológico y de diferenciación con los bolcheviques que en los aspectos históricos. Sin embargo, Taibo no obvia los antecedentes y establece unos interesantes análisis sobre cuestiones como el populismo, las organizaciones como el mir, el soviet o el zemtsvo. Además, dentro del campo puramente político, Taibo distingue entre lo "anarquista", que ubica en el campo doctrinal y organizativo, y lo "libertario", que hace mucho más extensivo y donde se pueden ubicar experiencias que no están estrictamente relacionadas con la organización política del anarquismo. Taibo completa con este libro otros estudios sobre la historia de la Unión Soviética o los conflictos surgidos en la Europa del Este tras la caída del mundo socialista, mostrando un conocimiento exhaustivo de la zona.

Ambos libros han rescatado una arista de la Revolución rusa desconocida y han demostrado la importancia que tuvo en el momento de producirse los acontecimientos. Además, tanto Taibo como Vadillo (al igual

103 Julián Vadillo Muñoz, Por el pan, la tierra y la libertad. El anarquismo en la Revolución rusa (Guadalajara: Volapük Ediciones, 2017).

104 Ibídem, 16.

105 Carlos Taibo, Anarquismo y revolución en Rusia, 1917-1921 (Madrid: Los Libros de la Catarata, 2017). 
que anteriormente Faraldo) conocen la lengua rusa, lo que les ha permitido acceder a documentos y material de primera mano en la lengua materna de aquel proceso.

En definitiva, sorprende que una temática como la Revolución rusa, que apenas había sido objeto de estudio durante años en nuestro país por parte de los investigadores, se esté mostrando como una nueva línea de investigación.

\section{Conclusiones}

Al realizar un estudio introductorio bibliográfico sobre las aportaciones historiográficas de la Revolución rusa se es consciente de que muchas cosas van a quedar en el tintero. Estamos hablando de un proceso que cambió la fisonomía del mundo y que ha sido objeto de miles de obras y de interpretaciones desde el mismo momento de su desarrollo. Además, como acontecimiento trascendental, esa historia a veces ha estado bajo la espada de Damocles de los combates políticos. Era usual durante mucho tiempo que ser crítico con la Revolución rusa valiese el apelativo de "anticomunista" (en muchos casos fue cierto) y que ser benevolente con el proceso confiriera la vitola de "comunista" o "revolucionario". El mundo surgido tras la Revolución de 1917 y, sobre todo, tras la Segunda Guerra Mundial fue bipolar en estos aspectos. Y eso hizo que se perdiese una riqueza y complejidad que algunas de las nuevas investigaciones sí han planteado. Sin embargo, la Revolución rusa no ha dejado de tener un estigma, y el colapso y la caída de la URSS posibilitaron el nacimiento de toda una historiografía conservadora que se fijó, sobre todo, en los aspectos negativos de la revolución, muchas veces sobredimensionados o directamente descontextualizados. A este debate ha contribuido también cierta historiografía marxista que ha sido más hagiográfica que histórica y también ha desfigurado el acontecimiento.

Hemos tenido la suerte de vivir de cerca los acontecimientos alrededor del centenario de la Revolución de 1917 y hemos podido comprobar la riqueza que atesoraban los testimonios de los contemporáneos de la revolución, de los que escribieron y reflexionaron sobre el acontecimiento cuando este estaba en pleno desarrollo. También hemos podido ver cómo 
hay clásicos que siempre van a tener vigencia, sean de la escuela que sean. Y cómo las nuevas aportaciones en muchas ocasiones han venido a reproducir debates de antaño, pero también a aportar nuevas perspectivas de investigación. Por ello era importante plasmar esas otras aristas de la revolución, aunque somos conscientes de que algunas, como el cine o el arte, no se han podido incluir a pesar de existir obras interesantes como las de Tzevetan Todorov.

Hablar de la historiografía de la Revolución rusa daría para un volumen. Analizar pormenorizadamente todas y cada una de las obras que se han editado al respecto, con sus visiones y sus temáticas, en los distintos idiomas, daría para varios tomos. Aquí se han marcado las principales aportaciones y líneas de investigación de una revolución que, tras cien años, sigue estando en permanente debate.

\section{Bibliografía}

Aguilar Mora, Manuel. 2017. Trostky y su Historia de la revolución rusa, conferencia en la Universidad de Guanajuato el 29 de octubre. http://www.sinpermiso.info/textos/ trotsky-y-su-historia-de-la-revolucion-rusa.

Amin, Samir. 2017. La Revolución de Octubre cien años después. Barcelona: El Viejo Topo. Andrade, Juan, y Fernando Hernández Sánchez, coord. 2017.1917. La Revolución rusa cien años después. Madrid: Akal.

Anweiler, Oskar. 1975. Los soviets en Rusia. Bilbao: Zero ZYX.

Archinov, Piotr. 1975. Historia del movimiento macknovista. Barcelona: Tusquets.

Arendt, Hanna. 2006. Los orígenes del totalitarismo. Madrid: Alianza.

Avilés Farré, Juan. 1999. La fe que vino de Rusia. La revolución bolchevique y los españoles (1917-1931). Madrid: Biblioteca Nueva / UNED.

Botchkareva, Maria. 1930. El Batallón de Mujeres de la Muerte. Madrid / Barcelona / Buenos Aires: Mundo Latino.

Brinton, Maurice. 1972. Los bolcheviques y el control obrero, 1917-1921. El Estado y la contrarrevolución. París: Ruedo Ibérico.

Broué, Pierre. 1963. Le parti bolchevique. Histoire du PC de l'URSS. París: Les Éditions de Minuit.

—.1964. Los procesos de Moscú. Barcelona: Anagrama.

-1974. El Partido Bolchevique. Madrid: Ayuso.

-1997. Histoire de l'International Communiste, 1919-1945. París: Fayard.

- 2003. Communiste contre Staline. Massacre d’une génération. París: Fayard.

Carr, Edward Hallett. 1970. Estudios sobre la revolución. Madrid: Alianza. 
Carr, Edward Hallett. 1977. La Revolución Bolchevique, 1917-1923. Madrid: Alianza.

—.1980-1984. Historia de la Rusia soviética, 4 tomos. Madrid: Alianza.

-1985. La Revolución rusa de Lenin a Stalin, 1917-1929. Madrid: Alianza.

Casanova, Julián. 2017. La venganza de los siervos. Rusia, 1917. Barcelona: Crítica.

Chamberlin, William Henry. 1987. The Russian Revolution: 1917-1921. Nueva Jersey: Princeton University Press.

Chernichevsky, Nicolai. 1984. ¿Qué hacer? Barcelona: Júcar.

Cohen, Stephen F. 2017. Bujarin y la revolución bolchevique. Biografia politica, 1888 1938. Madrid: Siglo XXI.

Díez del Corral, Francisco. 1998. La Revolución rusa. Madrid: Anaya.

Faraldo, José María. 2017. La Revolución rusa. Historia y memoria. Madrid: Alianza.

Faulkner, Neil. 2017. La Revolución rusa. Una historia del pueblo. Madrid: Capitán Swing.

Figes, Orlando. 200o. La Revolución rusa (1890-1924). La tragedia de un pueblo.

Barcelona: Edhasa.

Figner, Vera. s/a. Rusia en las tinieblas. Memorias de una nihilista. Madrid: Zeus.

Fontana, Josep. 2017. El siglo de la Revolución. Una historia del mundo desde 1914. Barcelona: Crítica.

Harris, James. 2017. El gran miedo. Una nueva interpretación del terror en la Revolución rusa. Barcelona: Crítica.

Herzen, Alexander. 2006. Crónica de un drama familiar. Barcelona: Alba.

- 2014. Doctor Krupov. Madrid: Ardicia.

Hill, Christopher. 1985. La Revolución rusa. Barcelona: Ariel.

Kennan, George F. 1956. Russia Leaves the War. Nueva Jersey: Princeton University Press.

- 1961. Russia and the West Under Lenin and Stalin. Boston: Little, Brown and Company.

Largo Alonso, María Teresa. 2017. La Revolución rusa. La fábrica de una nueva sociedad. Madrid: Los Libros de la Catarata.

Lewin, Moshe. 2005. El siglo soviético. ¿Qué sucedió realmente en la Unión Soviética? Barcelona: Crítica.

Luxemburg, Rosa. 1975. La Revolución rusa. Barcelona: Anagrama.

Mayer, Arno J. 2013. Las furias. Violencia y terror en las revoluciones francesa y rusa. Zaragoza: Servicio de Publicaciones de la Universidad de Zaragoza.

Merridale, Catherine. 2016. El tren de Lenin. Orígenes de la Revolución rusa. Barcelona: Crítica.

Mieville, China. 2017. Octubre. La historia de la Revolución rusa. Madrid: Akal.

Milosevich, Mira. 2017. Breve historia de la Revolución rusa. Barcelona: Galaxia Gutemberg.

Montefiore, Simón Sebag. 2016. Los Romanov, 1613-1918. Crítica: Barcelona.

Moorehead, Alan. 1958. La revolución rusa. Barcelona: Destino.

Pipes, Richard. 2016. La revolución rusa. Barcelona: Círculo de Lectores.

—. 2017. «Entrevista de Eduardo Lago a Richard Pipes». El País. Babelia, 27 ene.

Rappaport, Helen. 2017. Atrapados en la Revolución rusa. Madrid: Palabras.

Reed, John. 1998. Diez dias que estremecieron el mundo. Barcelona: Akal. 
Sadoul, Jacques. 2016. Cartas desde la revolución bolchevique. Madrid: Turner.

Sávinkov, Boris. 2017. Memorias de un terrorista. Barcelona: Dirección Única y La Cotali. Serge, Víctor. 1978. Mémoires d'un révolutionnaire. París: Seuil.

- 2011. El año I de la Revolución rusa. Buenos Aires: RYR.

- 2011. El destino de una revolución. Barcelona: Libros de la Frontera.

- 2013. El caso Tulayev. Madrid: Capitán Swing.

- 2016. Medianoche en el siglo. Madrid: Alianza.

- 2017. Ciudad conquistada. Barcelona: Página Indómita.

Service, Robert. 1999. The Russian Revolution, 1900-1927. Basingstoke: Palgrave Macmillan.

- 2000. Historia de Rusia en el siglo $x x$. Barcelona: Crítica.

- 2004. Lenin. Una biografía. Madrid: Siglo xxI.

-2005. Rusia. Experimento con un pueblo. Madrid: Siglo XxI.

- 2006. Stalin. Una biografía. Madrid: Siglo xxI.

- 2010. Trotsky. Una biografia. Barcelona. Ediciones B.

Sokolov, Boris. 1920. Los bolchevikes juzgados por ellos mismo. Documentos de los soviets de 1919. Madrid. Juan Pueyo.

Sukhanov, Nikolai Nikolaevich. 1970. La revolución rusa (1917). Barcelona: Luis de Caralt.

Taibo, Carlos. 2017. Anarquismo y revolución en Rusia, 1917-1921. Madrid: Los Libros de la Catarata.

Trotsky, León. 1978. Mi vida. Madrid: Tebas. .1985. Historia de la revolución rusa, 3 vol. Madrid: Sarpe.

Tsvietáieva, Marina. 2015. Diarios de la Revolución de 1917. Barcelona: Acantilado.

Vadillo Muñoz, Julián. 2017. Por el pan, la tierra y la libertad. El anarquismo en la Revolución rusa. Guadalajara: Volapük Ediciones.

Veiga, Francisco, Pablo Martín y Juan Sánchez Monroe. 2017. Entre dos octubres. Revoluciones y contrarrevoluciones en Rusia (1905-1917) y Guerra Civil en Eurasia. Madrid: Alianza.

Volin [Vsevolod Mijailovich Eichembaum]. 1977. La revolución desconocida (1917-1921). Documentación inédita sobre la revolución rusa, 2 vol. Madrid: Campo Abierto.

Wolfe, Bertram. 1948. Three Who Made a Revolution. A Biographical History. Washington: Dial Press. 